\title{
Management Guidelines for Patients with Thyroid Nodules and Differentiated Thyroid Cancer
}

\author{
The American Thyroid Association Guidelines Taskforce*
}

\author{
Members: David S. Cooper, ${ }^{1}$ (Chair), Gerard M. Doherty, ${ }^{2}$ Bryan R. Haugen, ${ }^{3}$ Richard T. Kloos, ${ }^{4}$ \\ Stephanie L. Lee, ${ }^{5}$ Susan J. Mandel, ${ }^{6}$ Ernest L. Mazzaferri, ${ }^{7}$ Bryan Mclver, ${ }^{8}$ Steven I. Sherman, ${ }^{9}$ \\ and R. Michael Tuttle ${ }^{10}$
}

\section{Contents}

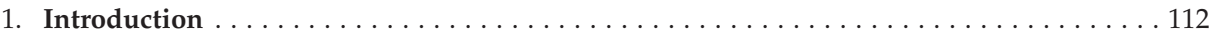

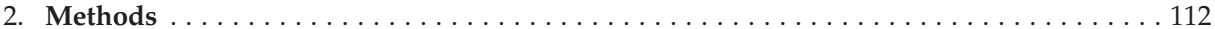

a. Literature search strategy

b. Evaluation of the evidence

3. Thyroid Nodules $\ldots \ldots \ldots \ldots$
a. Thyroid nodule evaluation

a. Thyroid nodule evaluation
i. Laboratory studies

ii. Fine needle aspiration biopsy

iii. Multinodular goiter

b. Thyroid nodule follow up and treatment

i. Long-term follow-up

ii. Role of medical therapy

iii. Thyroid nodules and pregnancy

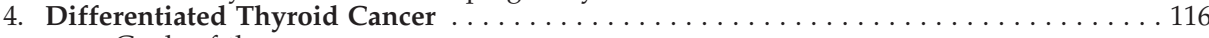

a. Goals of therapy

b. Role of preoperative staging with diagnostic testing

c. Surgery for differentiated thyroid cancer

i. Extent of initial surgery

ii. Completion thyroidectomy

d. Pathological and clinical staging systems

e. Postoperative radioiodine remnant ablation

i. Modes of thyroid hormone withdrawal

ii. Role of diagnostic scanning before ablation

iii. Radioiodine ablation dosage

iv. Use of recombinant human thyrotropin for remnant ablation

v. Role of low iodine diets

vi. Performance of post therapy scans

f. Thyroxine suppression therapy

g. Role of adjunctive external beam radiation or chemotherapy

5. Differentiated Thyroid Cancer: Long-Term Management

a. Risk stratification for follow-up intensity

b. Utility of serum thyroglobulin measurements

c. Role of diagnostic radioiodine scans, ultrasound, and other imaging techniques

d. Long-term thyroxine suppression therapy

e. Management of patients with metastatic disease

i. Locoregional recurrence

1. Surgery

2. Radioiodine therapy

ii. Distant metastatic disease

1. Pulmonary metastases

2. Bone metastases

3. Brain metastases

iii. Complications of radioactive iodine treatment

f. Management of thyroglobulin positive patients

g. Role of external beam radiotherapy

h. Role of chemotherapy

6. Directions for Future Research

\footnotetext{
${ }^{2}$ University of Michigan Medical Center, Ann Arbor, Michigan.

${ }^{3}$ University of Colorado Health Sciences Center, Denver, Colorado.

${ }^{4}$ Ohio State University School of Medicine and Public Health, Columbus, Ohio.

${ }^{5}$ Boston University Medical Center, Boston, Massachusetts.

${ }^{6}$ University of Pennsylvania School of Medicine, Philadelphia, Pennsylvania.

${ }^{7}$ University of Florida College of Medicine, Gainesville, Florida.

${ }^{8}$ The Mayo Clinic, Rochester, Minnesota.

${ }^{9}$ University of Texas, M.D. Anderson Cancer Center, Houston, Texas.

${ }^{10}$ Memorial Sloan-Kettering Cancer Center, New York, New York.

*Taskforce members are listed in alphabetical order.
}

${ }^{1}$ Sinai Hospital of Baltimore and Johns Hopkins University School of Medicine, Baltimore, Maryland. 


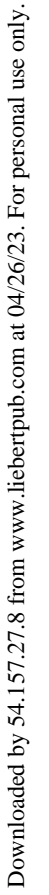




\title{
Thyroid Cancer Guidelines
}

\author{
Task Force Disclosure Information
}

\author{
David S. Cooper, MD ${ }^{1}$ \\ Gerard M. Doherty, MD ${ }^{1}$ \\ Bryan Haugen, MD 2, 3 \\ Richard T. Kloos, MD 3, 4 \\ Stephanie Lee, MD, PhD 5 \\ Susan Mandel, MD, MPH 5, 6 \\ Ernest L. Mazzaferri, MD ${ }^{7}$ \\ Bryan McIver, MD, PhD ${ }^{1}$ \\ Steven I. Sherman, MD 8, 9, 10 \\ R. Michael Tuttle, MD 11, 12
}

\footnotetext{
${ }^{1}$ No financial interests, arrangements, or affiliations with the manufacturer of any products or devices to be discussed in these guidelines.

2 Speakers Bureau and CME Faculty: Genzyme Corp.

${ }^{3}$ Consultant, Speakers Bureau and CME Faculty: Abbott Laboratories

${ }^{4}$ Grant/Research Support, Consultant, Speakers Bureau and CME Faculty: Genzyme Corp.

${ }^{5}$ CME Faculty: Abbott Laboratories

${ }^{6}$ Paid Consultant: King Pharmaceuticals, Inc.

7 Paid Consultant and Speakers Bureau: Genzyme Corp.

${ }^{8}$ CME Faculty: Abbott Laboratories, Genzyme Corp.

${ }^{9}$ Grant or Research Support: Genzyme Corp.

10 Paid Consultant: Abbott Laboratories

${ }^{11}$ Grant/Research Support, Consultant and CME Faculty: Genzyme Corp.

12 Speakers Bureau and CME Faculty: Abbott Laboratories
}

\section{The American Thyroid Association Disclosure Policy}

Standards and guidelines are to insure that individuals participating in professional activities are aware of author relationships with commercial companies that could potentially affect the information presented. The American Thyroid Association has endorsed the requirement that authors disclose any

significant financial interest or affiliations they may have with the manufacturers of products or devices that may be discussed in the development of guidelines.

In compliance with this policy, a superscript number placed by the name of an author denotes an author who has indicated an affiliation with organizations which have interests related to the content of these guidelines. The intent of this policy is to openly identify potential conflicts of interest so that

physicians may form their own judgments about the guidelines with full disclosure of the facts; it remains for the audience to determine whether an author's outside interest may reflect a possible bias in either the exposition or the conclusions presented. 


\section{Introduction}

T HYROID NODUles are a common clinical problem. Epidemiologic studies have shown the prevalence of palpable thyroid nodules to be approximately $5 \%$ in women and $1 \%$ in men living in iodine-sufficient parts of the world $(1,2)$. In contrast, high-resolution ultrasound can detect thyroid nodules in $19 \%-67 \%$ of randomly selected individuals with higher frequencies in women and the elderly (3). The clinical importance of thyroid nodules rests with the need to exclude thyroid cancer that occurs in 5\%-10\% depending on age, gender, radiation exposure history, family history, and other factors $(4,5)$. Differentiated thyroid cancer, which includes papillary and follicular cancer, comprises the vast majority $(90 \%)$ of all thyroid cancers (6). In the United States, approximately 23,500 cases of differentiated thyroid cancer are diagnosed each year (7), and the yearly incidence may be increasing (8).

In 1996, the American Thyroid Association (ATA) published treatment guidelines for patients with thyroid nodules and thyroid cancer (9). Over the last decade, there have been many advances in the diagnosis and therapy of both thyroid nodules and differentiated thyroid cancer. Controversy exists in many areas, including the most cost-effective approach in the diagnostic evaluation of a thyroid nodule, the extent of surgery for small thyroid cancers, the use of radioactive iodine to ablate remnant tissue after thyroidectomy, the appropriate use of thyroxine suppression therapy, and the role of human recombinant thyrotropin. In recognition of the changes that have taken place in the overall management of these clinically important problems, the ATA appointed a task force to reexamine the current strategies that are used to diagnose and treat thyroid nodules and differentiated thyroid cancer, and to develop clinical guidelines using principles of evidence-based medicine. Members of the taskforce included experts in thyroid nodule and thyroid cancer management with representation by endocrinology, surgery, and nuclear medicine. Other groups have previously developed guidelines, including the American Association of Clinical Endocrinologists and the American Association of Endocrine Surgeons (10), the British Thyroid Association and The Royal College of Physicians (11), and the National Comprehensive Cancer Network (12), which have provided somewhat conflicting recommendations because of the lack of high-quality evidence from randomized controlled trials.

\section{Materials and Methods}

The ATA guidelines taskforce used a strategy similar to that used by the National Institutes of Health for its Consensus Development Conferences (www.consensus.nih. gov/about/process.htm), and developed a series of clinically relevant questions pertaining to thyroid nodule and thyroid cancer diagnosis and treatment. These questions were as follows:

\section{Thyroid Nodules}

- What is the appropriate evaluation of clinically or incidentally discovered thyroid nodule(s)?

- What laboratory tests and imaging modalities are indicated?

- What is the role of fine needle aspiration (FNA)?
- What is the best method of long-term follow-up of patients with thyroid nodules?

- What is the role of medical therapy of patients with benign thyroid nodules?

- How should thyroid nodules in children and pregnant women be managed?

\section{Differentiated Thyroid Cancer: Initial Management}

- What is the role of preoperative staging with diagnostic imaging and laboratory tests?

- What is the appropriate operation for differentiated thyroid cancer?

- What is the role of postoperative staging systems and which should be used?

- What is the role of postoperative radioiodine remnant ablation?

- What is the role of thyrotropin suppression therapy?

- Is there a role for adjunctive external beam irradiation or chemotherapy?

\section{Differentiated Thyroid Cancer: Long-Term Management}

- What are the appropriate features of long-term management?

- What is the role of serum thyroglobulin assays?

- What is the role of ultrasound and other imaging techniques during follow-up?

- What is the role of thyrotropin suppression in long-term follow-up?

- What is the most appropriate management of patients with metastatic disease?

- How should thyroglobulin positive, scan negative patients be managed?

- What is the role of external radiation therapy

- What is the role of chemotherapy?

- What are directions for future research?

A 2-day meeting of the taskforce was held on January 21-23, 2005. Prior to the meeting, the taskforce members undertook a complete literature review. Relevant articles were identified by searching MEDLINE using the following search terms: \{THRYOID NODULE/diagnosis, drug therapy, surgery, therapy, ultrasonography\} or $\{$ CANCER\} or $\{\mathrm{CARCI}-$ NOMA $\}$ and \{THYROID\} and \{FOLLICULAR CARCINOMA $\}$ or $\{$ PAPILLARY CACINOMA $\}$ and $\{$ FOLLOW-UP\} and \{TREATMENT\} and \{RECURRENCE\}. All Englishlanguage papers published between 1995 and December 2004 were reviewed and categorized in tabular form by date, author, subject, and whether it represented a randomized controlled trial, meta-analysis, or clinical case series. Relevant review articles, book chapters, and pre-1995 articles were also supplied by taskforce members. The taskforce categorized the published data using modified criteria adopted from the U.S. Preventive Services Task Force (USPSTF) (13). The taskforce then made specific recommendations, rated the strength of the recommendation using the schema proposed by the USPSTF (Table 1). Given the paucity of randomized controlled trials in the treatment of thyroid cancer, the panel relied on all the available published evidence. When evidence was judged to be insufficient, the taskforce members also relied on their experience and judgment to answer the 
questions that had been posed. The taskforce met again in April 2005 and in June 2005 to refine the document and include new references. Supplementing these meetings were multiple teleconferences and detailed e-mail communications that continued through July 2005.

\section{Results}

\section{Thyroid nodules}

A thyroid nodule is a discrete lesion within the thyroid gland that is palpably and/or ultrasonographically distinct from the surrounding thyroid parenchyma. However, some palpable lesions may not correspond to distinct radiologic abnormalities (14). Such abnormalities do not meet the strict definition for thyroid nodules. Other nonpalpable nodules are easily seen on ultrasound or other anatomic imaging studies, and are termed incidentally discovered nodules or "incidentalomas." Nonpalpable nodules have the same risk of malignancy as palpable nodules with the same size (15). Generally, only nodules larger than $1 \mathrm{~cm}$ should be evaluated, because they have the potential to be clinically significant cancers. Occasionally, there may be nodules smaller than $1 \mathrm{~cm}$ that require evaluation, because of suspicious ultrasound findings, a history of head and neck irradiation, or a positive family history of thyroid cancer.

\section{What is the appropriate evaluation of clinically or incidentally discovered thyroid nodule(s)?}

With the discovery of a thyroid nodule, a complete history and physical examination focusing on the thyroid gland and adjacent cervical lymph nodes should be performed (Fig.
1). Pertinent historical factors predicting malignancy include a history of head and neck irradiation, total body irradiation for bone marrow transplantation (16), family history of thyroid carcinoma in a first-degree relative, exposure to fallout from Chernobyl under the age of 14 years (17), and rapid growth and hoarseness. Pertinent physical findings suggesting possible malignancy include vocal cord paralysis, ipsilateral cervical lymphadenopathy and fixation of the nodule to surrounding tissues.

\section{What laboratory tests and imaging modalities are indicated?}

Serum thyrotropin and imaging studies. With the discovery of a thyroid nodule larger than $1-1.5 \mathrm{~cm}$ in any diameter, a serum thyrotropin (TSH) level should be obtained. If the serum TSH is subnormal, a radionuclide thyroid scan should be obtained to document whether the nodule is functioning (i.e., has tracer uptake greater than the surrounding normal thyroid), isofunctioning or "warm" (i.e., has tracer uptake equal to the surrounding thyroid), or nonfunctioning (i.e., has uptake less than the surrounding thyroid tissue). Because functioning nodules rarely harbor malignancy, if one is found that corresponds to the clinical nodule, no additional cytologic evaluation is necessary. If overt or subclinical hyperthyroidism is present, additional evaluation is required.

R1. Measure serum TSH in the initial evaluation of a patient with a thyroid nodule-Recommendation C

Diagnostic thyroid ultrasound should be performed unless the serum TSH is suppressed. Thyroid ultrasound can

Table 1. Strength of Panelists' Recommendations Based on Available Evidence

Rating Definition

Strongly recommends. The recommendation is based on good evidence that the service or intervention can improve important health outcomes. Evidence includes consistent results from well-designed, well-conducted studies in representative populations that directly assess effects on health outcomes.

Recommends. The recommendation is based on fair evidence that the service or intervention can improve important health outcomes. The evidence is sufficient to determine effects on health

B outcomes, but the strength of the evidence is limited by the number, quality, or consistency of the individual studies; generalizability to routine practice; or indirect nature of the evidence on health outcomes.

C Recommends. The recommendation is based on expert opinion.

$\mathbf{D}$

Recommends against. The recommendation is based on expert opinion.

E

Recommends against. The recommendation is based on fair evidence that the service or intervention does not improve important health outcomes or that harms outweigh benefits.

$\mathbf{F}$

Strongly recommends against. The recommendation is based on good evidence that the service or intervention does not improve important health outcomes or that harms outweigh benefits.

Recommends neither for nor against. The panel concludes that the evidence is insufficient to recommend for or against providing the service or intervention because evidence is lacking that the service or intervention improves important health outcomes, the evidence is of poor quality, or the evidence is conflicting. As a result, the balance of benefits and harms cannot be determined. 


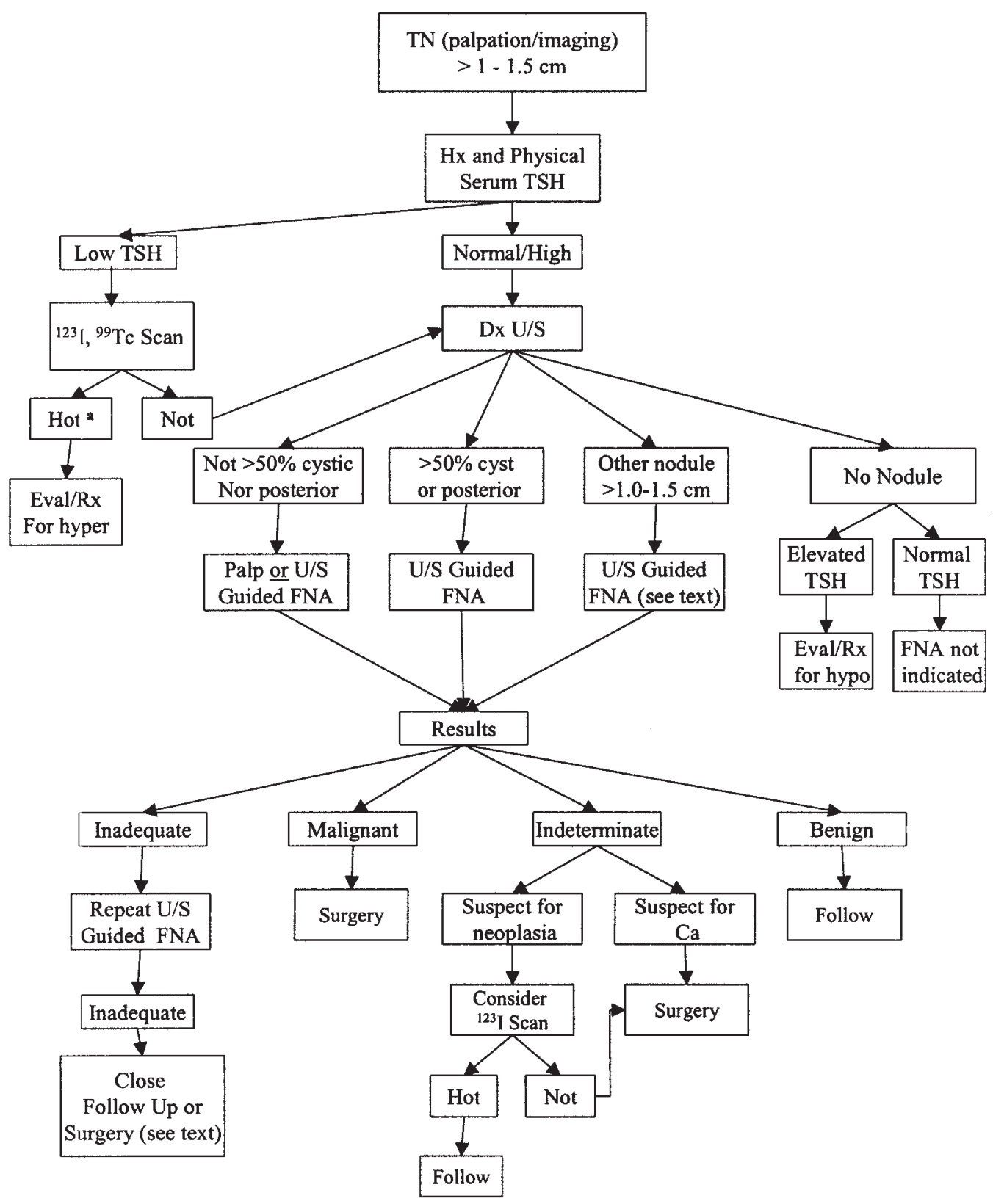

FIG. 1. Algorithm for the evaluation of patients with one or more thyroid nodules. ${ }^{\text {If }}$ the scan does not show uniform distribution of tracer activity, ultrasound may be considered to assess for the presence of a cystic component

answer the following questions: Is there truly a nodule that corresponds to the palpable abnormality? Is the nodule greater than $50 \%$ cystic? Is the nodule located posteriorly in the thyroid gland? These last two features might decrease the accuracy of fine needle aspiration biopsy performed with palpation $(18,19)$. Also, there may be other thyroid nodules present that require biopsy based on their size and appearance $(14,20,21)$. Even if the TSH is elevated, FNA is recommended because the rate of malignancy in nodules is similar in thyroid glands involved with Hashimoto's thyroiditis as in normal thyroid glands (22).

R2. Thyroid sonography should be performed in all patients with one or more suspected thyroid nodules-Recommendation $\mathrm{B}$

\section{Other laboratory testing:}

Serum thyroglobulin measurement. Serum thyroglobulin levels can be elevated in most thyroid diseases and is an insensitive and nonspecific test for thyroid cancer (23).

R3. Routine measurement of serum thyroglobulin for initial evaluation of thyroid nodules is not recommended-Recommendation $\mathrm{F}$

Serum calcitonin measurement. The utility of serum calcitonin has been evaluated in a series of prospective, nonrandomized studies (24-26). The data suggest that the use of routine serum calcitonin for screening may detect C-cell hyperplasia and medullary thyroid cancer at an earlier stage 
and overall survival may be improved. However, there remain unresolved issues of sensitivity, specificity, assay performance, and cost effectiveness. Furthermore, most studies rely on pentagastrin stimulation testing to increase specificity and this drug is no longer available in the United States. However, if the unstimulated serum calcitonin determination has been obtained and the level is greater than 100 $\mathrm{pg} / \mathrm{mL}$, medullary cancer is likely present (27).

$\mathrm{R} 4$. The panel cannot recommend either for or against the routine measurement of serum calcitonin-Recommendation I

\section{What is the role of FNA biopsy?}

FNA is the most accurate and cost effective method for evaluating thyroid nodules. Traditionally FNA biopsy results are divided into four categories: nondiagnostic, malignant, indeterminate or suspicious for neoplasm, and benign . Nondiagnostic biopsies are those that fail to meet specified criteria for adequacy that have been previously established (5). Such biopsies need to be repeated using ultrasound guidance (28). Some nodules, particularly those that are cystic, continue to yield nondiagnostic cytology results despite repeated biopsies, and may be malignant at the time of surgery $(29,30)$.

R5. FNA is the procedure of choice in the evaluation of thyroid nodules-Recommendation A

\section{Nondiagnostic aspirates}

R6. Cystic nodules that repeatedly yield nondiagnostic aspirates need close observation or surgical excision. Surgery should be more strongly considered if the cytologically nondiagnostic nodule is solid-Recommendation A

\section{Aspirates suggesting malignancy}

R7. If a cytology result is diagnostic of malignancy, surgery is recommended (31)-Recommendation A

\section{Indeterminate cytology}

Indeterminate cytology, often reported as "suspicious," "follicular lesion," or "follicular neoplasm," can often be found in $15 \%-30 \%$ of FNA specimens. While certain clinical features such as gender and nodule size (32) or cytologic features such as presence of atypia (33) can improve the diagnostic accuracy in patients with indeterminate cytology, overall predictive values are still low. Many molecular markers have been evaluated to improve diagnostic accuracy for indeterminate nodules $(34,35)$ but none can be recommended because of insufficient data.

R8. At the present time, the use of specific molecular markers to improve the diagnostic accuracy of indeterminate nodules is not recommended-Recommendation I

R9. If the cytology reading is indeterminate (often termed "suspicious," "follicular lesion," or "follicular neoplasm"), a radioiodine thyroid scan should be considered, if not already done. If a concordant autonomously functioning nodule is not seen, lobectomy or total thyroidectomy should be considered-Recommendation B
R10. If the reading is "suspicious for papillary carcinoma or Hürthle cell neoplasm," a radionuclide scan is not needed, and either lobectomy or total thyroidectomy is recommended-Recommendation A (36)

\section{Benign cytology}

R11. If the nodule is benign on cytology, further immediate diagnostic studies or treatment are not routinely requiredRecommendation A

\section{Multinodular goiters}

Patients with multiple thyroid nodules have the same risk of malignancy as those with solitary nodules $(14,37)$. A diagnostic ultrasound should be performed to delineate the nodules, but if only the "dominant" or largest nodule is aspirated, the thyroid cancer may be missed (14). Sonographic characteristics are superior to nodule size for identifying nodules that are more likely to be malignant $(37,38)$ and include the presence of microcalcifications, hypoechogenicity (darker than the surrounding thyroid parenchyma) of a solid nodule, and intranodular hypervascularity $(37,38)$. The detection of microcalcifications and nodular vascularity has good interobserver reliability (39).

R12a. In the presence of two or more thyroid nodules larger than 1-1.5 cm, those with a suspicious sonographic appearance should be aspirated preferentially—Recommendation B

R12b. If none of the nodules has a suspicious sonographic appearance and multiple sonographically similar coalescent nodules are present, the likelihood of malignancy is low and it is reasonable to aspirate the largest nodules only-Recommendation $\mathrm{C}$

R13. A low or low-normal serum TSH concentration may suggest the presence of autonomous nodule(s). A radioiodine scan should be performed and directly compared to the ultrasound images to determine functionality of each nodule larger than 1-1.5 cm. FNA should then be considered only for those isofunctioning or nonfunctioning nodules, among which those with suspicious sonographic features should be aspirated preferentially-Recommendation B

\section{What is the best method of long-term follow-up of patients with thyroid nodules?}

Thyroid nodules diagnosed as benign require follow-up because of a low, but not negligible, false-negative rate of up to $5 \%$ with FNA $(40,41)$. While benign nodules may decrease in size, they often increase in size, albeit slowly (42). Nodule growth is not in and of itself an indication of malignancy, but growth is an indication for repeat biopsy. For nodules with benign cytologic results, recent series report a higher false negative rate with palpation FNA $(1 \%-3 \%)(43-45)$ than with ultrasound FNA $(0.6 \%)(44)$. In one study investigating the value of routine reaspirations of benign nodules, the nodule grew in the three patients who were subsequently found to have thyroid cancer (37). Because the accuracy of physical examination for nodule size is likely inferior to that of ultrasound (21), it is recommended that serial ultrasound be used in follow-up of thyroid nodules to detect clinically sig- 
nificant changes in size. There is no consensus on the definition of nodule growth, however, or the threshold that would require rebiopsy. Some groups suggest a $15 \%$ increase in nodule volume, while others recommend measuring a change in the mean nodule diameter $(42,46)$. One reasonable definition of growth is a $20 \%$ increase in nodule diameter with a minimum increase in two or more dimensions of at least $2 \mathrm{~mm}$. The false-negative rate for benign thyroid nodules on repeat FNA is low (47).

R14. Easily palpable benign nodules do not require sonographic monitoring, but patients should be followed clinically at 6-18 month intervals. It is recommended that all other benign thyroid nodules be followed with serial ultrasound examinations 6-18 months after initial FNA. If nodule size is stable, the interval before the next follow-up clinical examination or ultrasound may be longer-Recommendation $B$

R15. If there is evidence for nodule growth either by palpation or sonographically, repeat FNA, preferably with ultrasound guidance-Recommendation $\mathrm{B}$

\section{What is the role of medical therapy for benign thyroid nodules?}

Evidence from multiple randomized control trials and three metaanalyses suggest that thyroid hormone in doses that suppress the serum TSH to subnormal levels may result in a decrease in nodule size in regions of the world with borderline low iodine intake. Data in iodine sufficient populations are less compelling (48-50).

R16. The panel does not recommend routine suppression therapy of benign thyroid nodules-Recommendation $\mathrm{F}$

R17. Patients with growing nodules that are benign after repeat biopsy should be considered for continued monitoring or intervention with surgery based on symptoms and clinical concern-Recommendation $C$. There are no data on the use of levothyroxine in this subpopulation of patients-Recommendation I

\section{How should thyroid nodules in children and pregnant women be managed?}

Thyroid nodules in children. Thyroid nodules occur less frequently in children than in adults. In one study in which approximately 5000 children aged 11 to 18 were assessed annually in the southwestern United States, palpable thyroid nodules occurred in approximately 20 per 1000 children, with an annual incidence of 7 new cases per 1000 children (51). Some studies have shown the frequency of malignancy to be higher in children than adults, in the $15 \%-20 \%$ range (52-54), whereas other data have suggested that the frequency of thyroid cancer in childhood thyroid nodules is similar to that of adults $(55,56)$. FNA biopsy is sensitive and specific in the diagnosis of childhood thyroid nodules (53-55).

R18. The diagnostic and therapeutic approach to one or more thyroid nodules in a child should be the same as it would be in an adult (clinical evaluation, serum TSH, ultrasound, FNA)-Recommendation A
Thyroid nodules in pregnant women. It is uncertain if thyroid nodules discovered in pregnant women are more likely to be malignant than those found in nonpregnant women (57), because there are no population-based studies on this question. The evaluation is the same as for a nonpregnant patient, with the exception that a radionuclide scan is contraindicated.

R19. For euthyroid and hypothyroid pregnant women with thyroid nodules, FNA should be performed. For women with suppressed serum TSH levels that persist after the first trimester, FNA may be deferred until after pregnancy when a radionuclide scan can be performed to evaluate nodule function-Recommendation A

If the FNA cytology is consistent with thyroid cancer, surgery is recommended. However, there is no consensus about whether surgery should be performed during pregnancy or after delivery. To minimize the risk of miscarriage, surgery during pregnancy should be done before 24 weeks' gestation (58). However, thyroid cancer discovered during pregnancy does not behave more aggressively than that diagnosed in a similar aged group of nonpregnant women $(59,60)$. A retrospective study of pregnant women with differentiated thyroid cancer found there to be no difference in either recurrence or survival rates between women operated on during or after their pregnancy (60). Furthermore, retrospective data suggest that treatment delays of less than 1 year from the time of thyroid cancer discovery do not adversely effect patient outcome (61).

R20. A nodule with malignant cytology discovered early in pregnancy should be monitored sonographically and if it grows substantially (as defined above) by 24 weeks' gestation, surgery should be performed at that point. However, if it remains stable by midgestation or if it is diagnosed in the second half of pregnancy, surgery may be performed after delivery-Recommendation C

\section{Differentiated Thyroid Cancer: Initial Management}

Goals of initial therapy of differentiated thyroid cancer are:

1. To remove the primary tumor, disease that has extended beyond the thyroid capsule, and involved cervical lymph nodes. Completeness of surgical resection is an important determinant of outcome, while residual metastatic lymph nodes represent the most common site of disease recurrence (62-64).

2. To minimize treatment- and disease-related morbidity. The extent of surgery and the experience of the surgeon both play important roles in determining the risk of surgical complications $(65,66)$.

3. To permit accurate staging of the disease. Because disease stage can assist with prognostication, disease management and follow-up strategies, accurate postoperative staging is a crucial element in the management of patients with differentiated thyroid cancer $(67,68)$.

4. To facilitate postoperative treatment with radioactive iodine, where appropriate. For patients undergoing radioiodine remnant ablation, or radioiodine treatment of residual or 
metastatic disease, removal of all normal thyroid tissue is an important element of initial surgery (69). Near-total or total thyroidectomy also may reduce the risk for recurrence within the contralateral lobe (70).

5. To permit accurate long-term surveillance for disease recurrence. Both radioiodine whole-body scanning and measurement of serum thyroglobulin are affected by residual normal thyroid tissue. Where these approaches are utilized for long-term monitoring, near-total or total thyroidectomy is required (71).

6. To minimize the risk of disease recurrence and metastatic spread. Adequate surgery is the most important treatment variable influencing prognosis, while radioactive iodine treatment, thyrotropin suppression and external beam irradiation each play adjunctive roles in at least some patients (71-74).

\section{What is the role of preoperative staging with diagnostic imaging and laboratory tests?}

Neck imaging. Differentiated thyroid carcinoma (particularly papillary carcinoma) involves cervical lymph nodes in $20 \%-50 \%$ of patients in most series using standard pathologic techniques (75-79), and may be present even when the primary tumor is small and intrathyroidal $(37,80)$. The frequency of micrometastases may approach $90 \%$, depending on the sensitivity of the detection method $(81,82)$. Preoperative ultrasound identifies suspicious cervical adenopathy in $20 \%-31 \%$ of cases, potentially altering the surgical approach $(83,84)$, although prospective studies are needed.

Accurate staging is important in determining the prognosis and tailoring treatment for patients with differentiated thyroid cancer. However, unlike many tumor types, the presence of metastatic disease does not obviate the need for surgical excision of the primary tumor in differentiated thyroid cancer (85). Because metastatic disease may respond to radioiodine therapy, removal of the thyroid as well as the primary tumor and accessible loco-regional disease remains an important component of initial treatment even in metastatic disease.

As ultrasound evaluation is uniquely operator dependent, alternative imaging procedures may be preferable in some clinical settings, though the sensitivity of computed tomography $(\mathrm{CT})$, magnetic resonance imaging (MRI), and positron emission tomography (PET) scan remain unknown in this setting. These alternative imaging modalities, as well as laryngoscopy and endoscopy, may also be useful in the assessment of large, rapidly growing, or invasive tumors, to assess the involvement of extrathyroidal tissues $(86,87)$.

R21. Preoperative neck ultrasound for the contralateral lobe and cervical (central and bilateral) lymph nodes is recommended for all patients undergoing thyroidectomy for malignant cytologic findings on biopsy-Recommendation B

R22. Routine preoperative use of other imaging studies (CT, MRI, PET) is not recommended-Recommendation E

Measurement of serum thyroglobulin. There is some evidence that high preoperative concentrations of serum thyroglobulin may predict a higher sensitivity for post-operative surveillance with serum thyroglobulin (88). Evidence that this impacts patient management or outcomes is not yet available.

R23. Routine preoperative measurement of serum thyroglobulin is not currently recommended-Recommendation $\mathrm{E}$

\section{What is the appropriate operation for differentiated thyroid cancer?}

Surgical options for indeterminate biopsies or biopsies diagnostic of differentiated thyroid carcinoma. The goal of thyroid surgery can include provision of a diagnosis after a nondiagnostic or indeterminate biopsy, removal of the thyroid cancer, staging, and preparation for radioactive ablation. Surgical options for thyroid cancer should be limited to lobectomy, near-total thyroidectomy (removal of all grossly visible thyroid tissue, leaving only a small amount ( $<1$ gram) of tissue adjacent to the insertion of the recurrent laryngeal nerve into the cricothyroid muscle), and total thyroidectomy (removal of all grossly visible thyroid tissue). Subtotal thyroidectomy, leaving more than 1 gram of tissue with the posterior capsule on the involved side, is an inappropriate operation for thyroid cancer (89).

Surgery for a nondiagnostic biopsy, a biopsy suspicious for papillary cancer, a biopsy suggestive of "follicular neoplasm," including special consideration for patients with other risk factors. Among solitary thyroid nodules with an indeterminate ("suspicious," "follicular neoplasm," or Hürthle cell neoplasm) biopsy, the risk of malignancy is approximately 20\% (90-92). For solitary nodules that are repeatedly nondiagnostic on biopsy, the risk of malignancy is unknown but is probably closer to $5 \%-10 \%$ (29).

R24. For patients with an isolated indeterminate solitary nodule who prefer a more limited surgical procedure, thyroid lobectomy is the recommended initial surgical approachRecommendation $\mathrm{C}$

R25. Because of an increased risk for malignancy, total thyroidectomy is indicated in patients with large tumors $(>4$ $\mathrm{cm}$ ) when marked atypia is seen on biopsy, when the biopsy reading is "suspicious for papillary carcinoma," in patients with a family history of thyroid carcinoma, and in patients with a history of radiation exposure $(32,93,94)$. Patients with bilateral nodular disease or those who prefer to undergo bilateral thyroidectomy to avoid the possibility of requiring a future surgery on the contralateral lobe should also undergo total thyroidectomy-Recommendation A

Surgery for a biopsy diagnostic for malignancy. Near-total or total thyroidectomy is recommended if any of the following are present: the primary thyroid carcinoma is more than 1-1.5 cm, contralateral thyroid nodules, regional or distant metastases, patient has a personal history of radiation therapy to the head and neck, or a first-degree family history of differentiated thyroid cancer. Older age ( $>45$ years) may also be a criterion for recommending near-total or total thyroidectomy because of higher recurrence rates in this age group $(62,68,69,95,96)$. Increased extent of primary surgery may improve survival for high-risk patients (97-99), while 
rates of recurrence are reduced by total- or near-total thyroidectomy even among low-risk patients $(68,100,101)$.

R26. For most patients with thyroid cancer, the initial surgical procedure should be a near-total or total thyroidectomy. Thyroid lobectomy alone may be sufficient treatment for small, low-risk, isolated, intrathyroidal papillary carcinomas in the absence of cervical nodal metastases-Recommendation A

Lymph node dissection. Regional lymph node metastases are present at the time of diagnosis in $20 \%-90 \%$ of patients with papillary carcinoma and a lesser proportion of patients with other histotypes $(75,102)$. In many cases, these lymph nodes do not appear abnormal to inspection (103). Bilateral central (compartment VI) node dissection may improve survival (compared to historic controls) and reduce the risk for nodal recurrence $(76,103)$. This central compartment dissection can be achieved with low morbidity in experienced hands (104-107).

R27. Routine central-compartment (level VI) neck dissection should be considered for patients with papillary thyroid carcinoma and suspected Hürthle carcinoma. Near-total or total thyroidectomy without central node dissection may be appropriate for follicular cancer, and when followed by radioactive iodine therapy, may provide an alternative approach for papillary and Hürthle cell cancers-Recommendation B

Lymph nodes in the lateral neck (compartments II-IV) and posterior triangle (compartment V) may also be involved by thyroid cancer, most often in papillary and Hürthle cell carcinoma $(75,108)$. For those patients in whom nodal disease is evident clinically, on preoperative ultrasound, or at the time of surgery, surgical resection may reduce the risk of recurrence and possibly mortality $(102,109,110)$. Functional compartmental en-bloc dissection is favored over selective dissection (berry picking) with limited data suggesting improved mortality $(64,111-113)$.

R28. Lateral neck compartmental lymph node dissection should be performed for patients with biopsy-proven metastatic cervical lymphadenopathy detected clinically or by imaging, especially when they are likely to fail radioactive iodine treatment based on lymph node size, number, or other factors, such as aggressive histology of the primary tumorRecommendation B

Completion thyroidectomy. Completion thyroidectomy may be necessary when the diagnosis of malignancy is made after lobectomy for an indeterminate or nondiagnostic biopsy. Some patients with malignancy may require completion thyroidectomy to provide complete resection of multicentric disease (114), and to allow radioiodine therapy. Most $(115,116)$ but not all $(114)$ studies of papillary cancer have observed a higher rate of cancer in the opposite lobe when multifocal ( $\geq 2$ foci), as opposed to unifocal, disease is present in the ipsilateral lobe. The surgical risks of two-stage thyroidectomy (lobectomy followed by completion thyroidectomy) are similar to those of a near-total or total thyroidectomy $(117,118)$.
R29. Completion thyroidectomy should be offered to those patients for whom a near-total or total thyroidectomy would have been recommended had the diagnosis been available before the initial surgery. This includes all patients with thyroid cancer except those with small $(<1 \mathrm{~cm})$, intrathyroidal, node-negative, low-risk tumors-Recommendation B

R30. Ablation of the remaining lobe with radioactive iodine has been used as an alternative to completion thyroidectomy (119). It is unknown whether this approach results in similar long term outcomes. Consequently, radioactive iodine ablation in lieu of completion thyroidectomy is not recommended-Recommendation E

\section{What is the role of postoperative staging systems and which should be used?}

The role of postoperative staging. Postoperative staging for thyroid cancer, as for other cancer types, is used: (1) to permit prognostication for an individual patient with differentiated thyroid carcinoma; (2) to tailor decisions regarding postoperative adjunctive therapy, including radioiodine therapy and thyrotropin suppression, to the patient's risk for disease recurrence and mortality; (3) to make decisions regarding the frequency and intensity of follow-up, directing more intensive follow-up towards patients at highest risk; and (4) to enable accurate communication regarding a patient between health care professionals. Staging systems also allow evaluation of differing therapeutic strategies applied to comparable groups of patients in clinical studies.

AJCC/UICC TNM staging. Application of the AJCC/UICC classification system based on pTNM parameters is recommended for tumors of all types, including thyroid cancer $(67,120)$, because it provides a useful shorthand method to describe the extent of the tumor (121) (Table 2). This classification is also used for hospital cancer registries and epidemiologic studies. In thyroid cancer, the AJCC/UICC Stage does not take account of several additional independent prognostic variables and may risk misclassification of some patients. Numerous other schemes have been developed in an effort to achieve more accurate risk factor stratification, including CAEORTC, AGES, AMES, U of C, MACIS, OSU, MSKCC, and NTCTCS systems $(61,62,68,98,122-125)$. These schemes take into account a number of factors identified as prognostic for outcome in multivariate analysis of retrospective studies, with the most predictive factors generally being regarded as the presence of distant metastases, the age of the patient, and the extent of the tumor. These and other risk factors are weighted differently among these systems according to their importance in predicting outcome but no scheme has demonstrated clear superiority (125). Nevertheless, each of the schemes allows accurate identification of the majority $(70 \%-85 \%)$ of patients at low-risk of mortality, allowing the follow-up and management of these patients to be less intensive than the higher risk minority, who may benefit from a more aggressive management strategy.

R31. Because of its utility in predicting disease mortality, and its requirement for cancer registries, AJCC/UICC staging is 
recommended for all patients with differentiated thyroid cancer. The use of postoperative clinicopathologic staging systems is also recommended to improve prognostication and to plan follow-up for patients with differentiated thyroid carcinoma-Recommendation $\mathrm{B}$

\section{What is the role of postoperative radioiodine remnant ablation?}

Postoperative radioiodine remnant ablation is increasingly being used to eliminate the post-surgical thyroid remnant. The goals of this treatment are to destroy residual thyroid tissue in an effort to decrease the risk for recurrent locoregional disease and to facilitate long-term surveillance with whole-body iodine scans and/or stimulated thyroglobulin measurements $(62,63)$. A number of large, retrospective studies show a significant reduction in the rates of disease recurrence $(61,98,99,126)$ and cause-specific mortality $(98,99,126-128)$. However, other similar studies show no such benefit, at least among the majority of patients with papillary thyroid carcinoma, who are at the lowest risk for mortality $(68,101,128-131)$. In those studies that show benefit, the advantage appears to be restricted to patients with larger tumors $(>1.5 \mathrm{~cm})$, or with residual disease after surgery, while lower risk patients do not show evidence for benefit $(68,98,132)$. No prospective studies have been performed to address this question (128).

R32. Radioiodine ablation is recommended for patients with stages III and IV disease (AJCC sixth edition; Table 2), all patients with stage II disease younger than age 45 years and most patients with stage II disease 45 years or older, and selected patients with stage I disease, especially those with multifocal disease, nodal metastases, extrathyroidal or vascular invasion, and/or more aggressive histologies-Recommendation B

\section{How should patients be withdrawn from thyroid hormone prior to radioiodine ablation?}

Remnant ablation (as well as subsequent monitoring for thyroid cancer persistence/recurrence using radioiodine

Table 2. TNM Classification System for Differentiated Thyroid Carcinoma

\begin{tabular}{|c|c|c|}
\hline \multicolumn{3}{|l|}{ Definition } \\
\hline $\mathrm{T} 1$ & \multicolumn{2}{|l|}{ Tumor diameter $2 \mathrm{~cm}$ or smaller } \\
\hline $\mathrm{T} 2$ & \multicolumn{2}{|l|}{ Primary tumor diameter $>2$ to $4 \mathrm{~cm}$} \\
\hline T3 & \multicolumn{2}{|c|}{ Primary tumor diameter $>4 \mathrm{~cm}$ limited to the thyroid or with minimal extrathyroidal extension } \\
\hline $\mathrm{T}_{\mathrm{a}}$ & \multicolumn{2}{|c|}{$\begin{array}{l}\text { Tumor of any size extending beyond the thyroid capsule to invade subcutaneous soft tissues, larynx, } \\
\text { trachea, esophagus, or recurrent laryngeal nerve }\end{array}$} \\
\hline $\mathrm{T} 4_{\mathrm{b}}$ & \multicolumn{2}{|c|}{ Tumor invades prevertebral fascia or encases carotid artery or mediastinal vessels } \\
\hline TX & \multicolumn{2}{|c|}{ Primary tumor size unknown, but without extrathyroidal invasion } \\
\hline $\mathrm{NO}$ & \multicolumn{2}{|l|}{ No metastatic nodes } \\
\hline $\mathrm{N} 1_{\mathrm{a}}$ & \multicolumn{2}{|c|}{ Metastases to level VI (pretracheal, paratracheal, and prelaryngeal/Delphian lymph nodes) } \\
\hline $\mathrm{N} 1_{\mathrm{b}}$ & \multicolumn{2}{|c|}{ Metastasis to unilateral, bilateral, contralateral cervical or superior mediastinal mode metastases } \\
\hline NX & \multicolumn{2}{|c|}{ Nodes not assessed at surgery } \\
\hline $\mathrm{MO}$ & \multicolumn{2}{|l|}{ No distant metastases } \\
\hline M1 & \multicolumn{2}{|l|}{ Distant metastases } \\
\hline MX & \multicolumn{2}{|l|}{ Distant metastases not assessed } \\
\hline \multicolumn{2}{|r|}{ 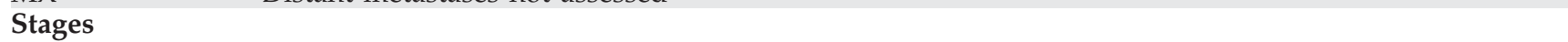 } & Patient aged 45 years or older \\
\hline Stage I & Any $\mathrm{T}$, any $\mathrm{N}, \mathrm{MO}$ & $\mathrm{T} 1, \mathrm{NO}, \mathrm{MO}$ \\
\hline Stage II & Any $\mathrm{T}$, any $\mathrm{N}, \mathrm{M} 1$ & $\mathrm{~T} 2, \mathrm{NO}, \mathrm{MO}$ \\
\hline Stage III & & $\begin{array}{l}\mathrm{T} 3, \mathrm{NO}, \mathrm{MO} \\
\mathrm{T} 1, \mathrm{~N} 1_{\mathrm{a}}, \mathrm{MO} \\
\mathrm{T} 2, \mathrm{~N} 1_{\mathrm{a}}, \mathrm{MO} \\
\mathrm{T} 3, \mathrm{~N} 1_{\mathrm{a}}, \mathrm{MO}\end{array}$ \\
\hline $\begin{array}{l}\text { Stage } \\
\text { IVA }\end{array}$ & & $\begin{array}{l}\mathrm{T} 4_{\mathrm{a}}, \mathrm{NO}, \mathrm{MO} \\
\mathrm{T} 4_{\mathrm{a}}, \mathrm{N} 1_{\mathrm{a}}, \mathrm{MO} \\
\mathrm{T} 1, \mathrm{N1}_{\mathrm{b}}, \mathrm{MO} \\
\mathrm{T} 2, \mathrm{~N}_{\mathrm{b}}, \mathrm{MO} \\
\mathrm{T} 3, \mathrm{~N}_{\mathrm{b}}, \mathrm{MO} \\
\mathrm{T} 4_{\mathrm{a}}, \mathrm{N} 1_{\mathrm{b}}, \mathrm{MO}\end{array}$ \\
\hline $\begin{array}{l}\text { Stage } \\
\text { IVB }\end{array}$ & & $\mathrm{T}_{\mathrm{b}}$, Any $\mathrm{N}, \mathrm{MO}$ \\
\hline $\begin{array}{l}\text { Stage } \\
\text { IVC }\end{array}$ & & Any T, Any N, M1 \\
\hline
\end{tabular}

Used with permission of the American Joint Committee on Cancer (AJCC), Chicago, Illinois.

The original source for this material is the AJCC Cancer Staging Manual, Sixth Edition (2002). Published by Springer-Verlag, New York, Inc. 
whole-body scans (WBS) and/or serum thyroglobulin measurement) requires TSH stimulation. No controlled studies have been performed to assess adequate levels of endogenous TSH for optimal ablation therapy or follow-up testing. Noncontrolled studies suggest that a TSH of more than 30 $\mathrm{mU} / \mathrm{L}$ is associated with increased radioiodine uptake in tumors (133), while studies using single-dose exogenous TSH suggest maximal thyrocyte stimulation at TSH levels between 51-82 mU/L (134,135). Endogenous TSH elevation can be achieved by two basic approaches to thyroid hormone withdrawal, stopping levothyroxine $\left(\mathrm{LT}_{4}\right)$ and switching to levotriiodothyronine $\left(\mathrm{LT}_{3}\right)$ for $2-4$ weeks followed by withdrawal of triiodothyronine $\left(\mathrm{T}_{3}\right)$ for 2 weeks, or discontinuation of $\mathrm{LT}_{4}$ for 3 weeks without use of $\mathrm{T}_{3}$. Both methods of preparation can achieve serum TSH levels greater than 30 $\mathrm{mU} / \mathrm{L}$ in greater than $90 \%$ of patients (135-144). These two approaches have not been directly compared for efficiency of patient preparation (efficacy of ablation, iodine uptake, thyroglobulin levels, disease detection, or symptoms). Other preparative approaches have been proposed, but have not been validated by other investigators $(145,146)$.

R33. Patients undergoing radioiodine therapy or diagnostic testing can be prepared by $\mathrm{LT}_{4}$ withdrawal for at least 3 weeks or $\mathrm{T}_{3}$ treatment for $2-4$ weeks and $\mathrm{T}_{3}$ withdrawal for 2 weeks with measurement of serum TSH to determine timing of testing or therapy $(\mathrm{TSH}>30 \mathrm{mU} / \mathrm{L})$ - Recommendation $\mathrm{B}$

\section{Should radioiodine scanning be performed before radioiodine ablation?}

Radioiodine WBS provides information on the presence of iodine-avid thyroid tissue, which may represent the normal thyroid remnant or the presence of residual disease in the postoperative setting. In the presence of a large thyroid remnant, the scan is dominated by uptake within the remnant, potentially masking the presence of extrathyroidal disease within locoregional lymph nodes, the upper mediastinum or even at distant sites, reducing the sensitivity of disease detection (147). Furthermore, there is an increasing trend to avoid pretherapy radioiodine scans altogether because of concerns over ${ }^{131}$ I-induced stunning of thyroid cancer (148). Stunning is defined as a reduction in uptake of the ${ }^{131}$ I therapy dose induced by a pretreatment diagnostic dose. Stunning occurs most prominently with higher doses $(5-10 \mathrm{mCi})$ of ${ }^{131}$ I (149), with increasing time between the diagnostic dose and therapy (150), and is not visually appreciated at lower doses (1-3 mCi). However, the accuracy of low-dose ${ }^{131}$ I scans has been questioned, and some have reported quantitatively the presence of stunning below the threshold of visual detection (151). Although comparison studies show excellent concordance between ${ }^{123} \mathrm{I}$ and ${ }^{131} \mathrm{I}$ for tumor detection, optimal ${ }^{123} \mathrm{I}$ activity and time to scan after ${ }^{123} \mathrm{I}$ administration is not known (152). Furthermore, ${ }^{123} \mathrm{I}$ is expensive, is not universally available, its short half life $\left(t_{1 / 2}=13\right.$ hours) makes handling this isotope more difficult (153), and stunning may also occur though to a lesser degree than with ${ }^{131}$ I (150). Determination of the thyroid bed uptake can be achieved using $10-100 \mu \mathrm{Ci}{ }^{131} \mathrm{I}$.

R34. Pretherapy scans and/or measurement of thyroid bed uptake may be useful when the extent of the thyroid rem- nant cannot be accurately ascertained from the surgical report or neck ultrasonography, or when the results would alter either the decision to treat or the activity of radioiodine that is administered. If performed, pretherapy scans should utilize low-dose ${ }^{131} \mathrm{I}(1-3 \mathrm{mCi})$ or ${ }^{123} \mathrm{I}$-Recommendation $\mathrm{C}$

\section{What activity of 131 / should be used for remnant ablation?}

Successful remnant ablation is usually defined as an absence of visible radioiodine uptake on a subsequent diagnostic radioiodine scan. Activities between 30 and $100 \mathrm{mCi}$ of ${ }^{131}$ I generally show similar rates of successful remnant ablation (154-157), although there is a trend toward higher success rates with higher activities (158).

R35. The minimum activity (30-100 $\mathrm{mCi})$ necessary to achieve successful remnant ablation should be chosen, particularly for low-risk patients-Recommendation B

R36. If residual microscopic disease is suspected or documented, or if there is a more aggressive tumor histology (e.g. tall cell, insular, columnar cell carcinoma) , then higher activities (100- $200 \mathrm{mCi}$ ) may be appropriate-Recommendation C

\section{Can recombinant human thyrotropin (Thyrogen ${ }^{T M}$ ) be used in lieu of thyroxine withdrawal for remnant ablation?}

There is limited experience with the use of recombinant human thyrotropin (rhTSH) in radioiodine ablation of postsurgical thyroid remnants. Some patients, unable to tolerate hypothyroidism or unable to generate an elevated TSH, have undergone successful remnant ablation with rhTSH $(159,160)$. Successful remnant ablation with $30 \mathrm{mCi}^{131} \mathrm{I}$ was equivalent after thyroxine withdrawal compared to rhTSH stimulation when the thyroxine therapy was stopped 1 day prior to the rhTSH injections and restarted the day after ${ }^{131} \mathrm{I}$ therapy (161). rhTSH is not approved in the United States for this indication, but it is approved in Europe.

R37. Remnant ablation can be performed following thyroxine withdrawal or rhTSH stimulation-Recommendation $\mathrm{B}^{\mathrm{a}}$

\section{Is a low-iodine diet necessary before remnant ablation?}

The efficacy of radioactive iodine depends on the radiation dose delivered to the thyroid tissue (162). Low-iodine diets ( $<50 \mu \mathrm{g} / \mathrm{d}$ of dietary iodine) have been recommended prior to radioiodine therapy (162-164), to increase the effective radiation dose. Measurement of iodine excretion may be a useful way to identify patients whose iodine intake could interfere with radioiodine remnant ablation (164).

R38. A low-iodine diet for 1-2 weeks is recommended for patients undergoing radioiodine remnant ablation, particularly for those patients with high iodine intake-Recommendation B

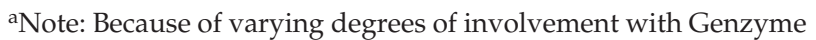
Corporation, the manufacturer of rhTSH (Thyrogen), the following authors recused themselves from the discussion of this recommendation: Bryan Haugen, M.D.; Richard Kloos, M.D.; Ernest Mazzaferri, M.D.; Steven Sherman, M.D.; and R. Michael Tuttle, M.D. 


\section{Should a posttherapy scan be performed after remnant ablation?}

Posttherapy whole body iodine scanning is typically conducted approximately 1 week after radioactive iodine therapy to visualize metastases. Additional metastatic foci have been reported in 10\%-26\% of patients scanned after highdose radioiodine treatment compared to the diagnostic scan $(165,166)$. The new abnormal uptake was found most often in the neck, lungs and mediastinum, and the newly discovered disease altered the disease stage in approximately $10 \%$ of the patients, affecting clinical management in $9 \%-15 \%$ (165-167).

R39. A posttherapy scan is recommended after radioiodine remnant ablation. This is typically done 5-8 days after the therapeutic dose is administered, although published data supporting this time interval are lacking-Recommendation B

\section{What is the role of TSH suppression therapy?}

Differentiated thyroid cancer expresses the thyrotropin receptor on the cell membrane, and responds to TSH stimulation by increasing the expression of several thyroid-specific proteins (thyroglobulin, sodium iodide symporter) and by increasing the rates of cell growth. Suppression of TSH, using supraphysiologic doses of $\mathrm{LT}_{4}$, is used commonly to treat patients with thyroid cancer in an effort to decrease the risk of recurrence $(73,168)$. A recent meta-analysis supported the efficacy of TSH suppression therapy in preventing major adverse clinical events (relative risk $[R R]=0.73$; confidence interval $[\mathrm{CI}]=0.60-0.88 ; p<0.05)(168)$.

\section{What is the appropriate degree of initial TSH suppression?}

Retrospective studies have demonstrated that TSH suppression to below $0.1 \mathrm{mU} / \mathrm{L}$ may improve outcomes in highrisk patients with thyroid cancer $(73,169)$, although no such evidence of benefit has been documented in low-risk patients. Adverse effects of TSH suppression may include the known consequences of subclinical thyrotoxicosis, including exacerbation of angina in patients with ischemic heart disease, increased risk for atrial fibrillation, and increased risk of osteoporosis in postmenopausal women (170).

R40. Initial thyrotropin suppression to below $0.1 \mathrm{mU} / \mathrm{L}$ is recommended for high-risk patients with thyroid cancer, while maintenance of the TSH at or slightly below the lower limit of normal $(0.1-0.5 \mathrm{mU} / \mathrm{L})$ is appropriate for low-risk patients-Recommendation $\mathrm{B}$

\section{Is there a role for adjunctive external beam irradiation or chemotherapy?}

External beam irradiation. External beam irradiation is used infrequently in the management of thyroid cancer except as a palliative treatment for locally advanced, otherwise unresectable disease (171). There are reports of responses among patients with locally advanced disease $(172,173)$, and improved relapse-free and cause-specific survival (174). It remains unknown whether external beam radiation might re- duce the risk for recurrence in the neck after adequate primary surgery and/or radioiodine treatment.

R41. The use of external beam irradiation should be considered in patients over age 45 with grossly visible extrathyroidal extension at the time of surgery and a high likelihood of microscopic residual disease, and for those patients with gross residual tumor in whom further surgery or radioactive iodine would likely be ineffective-Recommendation B

Chemotherapy. There are no data to support the use of adjunctive chemotherapy in the management of differentiated thyroid cancer. Doxorubicin (adriamycin) may act as a radiation sensitizer in some tumors of thyroid origin $(175,176)$, and could be considered for patients with locally advanced disease undergoing external beam radiation.

R42. There is no role for the routine adjunctive use of chemotherapy in patients with differentiated thyroid cancerRecommendation F

\section{Differentiated Thyroid Cancer: Long-Term Management}

What are the appropriate features of long-term management?

Accurate surveillance for possible recurrence in patients thought to be free of disease is a major goal of long-term follow up. Tests with high negative predictive value allow identification of patients unlikely to experience disease recurrence, so that less aggressive management strategies can be used that may be more cost effective and safe. Similarly, patients with a higher risk of recurrence are monitored more aggressively, based on the admittedly unproven premise, that early detection of recurrent disease offers the best opportunity for effective treatment. Patients with persistent or recurrent disease are offered treatment to cure or to delay future morbidity or mortality. In the absence of such options, therapies to palliate by substantially reducing tumor burden or preventing tumor growth are utilized, with special attention paid to tumor-threatening critical structures.

Follow-up is different for patients at low, intermediate, and at high risk of having persistent or recurrent disease. AJCCIUCC staging was developed to predict risk for death, not recurrence. For assessment of risk of recurrence, a three level stratification can be used. Low-risk patients have the following characteristics after initial surgery and remnant ablation: no local or distant metastases; all macroscopic tumor has been resected, there is no tumor invasion of locoregional tissues or structures, the tumor does not have aggressive histology (e.g., tall cell, insular, columnar cell carcinoma) or vascular invasion, and, if ${ }^{131} \mathrm{I}$ is given, there is no ${ }^{131} \mathrm{I}$ uptake outside the thyroid bed on the first posttreatment wholebody radioiodine scan (RxWBS) (177-179). Intermediate-risk patients have microscopic invasion of tumor into the perithyroidal soft tissues at initial surgery or tumor with aggressive histology or vascular invasion (180-182). High-risk patients have macroscopic tumor invasion, incomplete tumor resection, distant metastases, or ${ }^{131}$ I uptake outside the thyroid bed on the post-treatment scan done after thyroid remnant ablation $(183,184)$. 
What is the appropriate method of following patients after surgery with or without remnant ablation?

Criteria for absence of persistent tumor. In patients who have undergone total or near-total thyroidectomy and thyroid remnant ablation, disease free status comprises all of the following: no clinical evidence of tumor, no imaging evidence of tumor (no uptake outside the thyroid bed on the initial posttreatment whole body scan, on a recent diagnostic scan or neck ultrasound), and undetectable serum thyroglobulin levels during TSH suppression and stimulation in the absence of interfering antibodies (Figs. 2 and 3).

\section{What is the role of serum thyroglobulin assays in the follow-up of differentiated thyroid cancer?}

Measurement of serum thyroglobulin levels is an important modality to monitor patients for residual or recurrent disease. Serum thyroglobulin has a high degree of sensitivity and specificity to detect thyroid cancer, especially after total thyroidectomy and remnant ablation, with the highest degrees of sensitivity noted after thyroid hormone withdrawal or stimulation using recombinant human thyrotropin (rhTSH) (185). Serum thyroglobulin measurements obtained during thyroid hormone suppression of TSH may fail to identify patients with relatively small amounts of residual tumor $(177,186)$. Conversely, even TSH-stimulated thyroglobulin measurement may fail to identify patients with clinically significant tumor, because of antithyroglobulin antibodies, or less commonly, defective or absent production and secretion of immunoreactive thyroglobulin by tumor cells (187). Thyroglobulin levels should be interpreted in light of the pretest probability of clinically significant residual tumor. An aggressive or poorly differentiated tumor may be present despite low basal or stimulated thyroglobulin; in contrast, a minimally elevated stimulated thyroglobulin may occur in patients at low risk for clinically significant morbidity (188).

Initial follow-up for low-risk patients (approximately 85\% of postoperative patients) who have undergone total or neartotal thyroidectomy and ${ }^{131} \mathrm{I}$ remnant ablation should be based mainly on TSH-suppressed thyroglobulin and cervical ultrasound, followed by TSH-stimulated serum thyroglobulin measurements if the TSH-suppressed thyroglobulin testing is undetectable $(177,186)$.

Approximately $20 \%$ of patients who are clinically free of disease with serum thyroglobulin levels less than $1 \mathrm{ng} / \mathrm{mL}$ during thyroid hormone suppression of TSH (186) will have a serum thyroglobulin level greater than $2 \mathrm{ng} / \mathrm{mL}$ after rhTSH or thyroid hormone withdrawal. In approximately one third of this group, persistent tumor can be identified on imaging studies. There is good evidence that a thyroglobulin cutoff level above $2 \mathrm{ng} / \mathrm{mL}$ after rhTSH stimulation is highly sensitive in identifying patients with persistent tumor $(186,189-194)$. However, the results of serum thyroglobulin measurements made on the same serum specimen differ among laboratories (88). Therefore, the thyroglobulin cutoff may differ slightly among medical centers and laboratories. Furthermore, the clinical significance of minimally detectable thyroglobulin levels is unclear, especially if only detected after TSH stimulation.

The presence of antithyroglobulin antibodies, which occur in approximately $25 \%$ of thyroid cancer (195) patients and
$10 \%$ of the general population (196), will falsely lower serum thyroglobulin determinations in immunometric assays (197). The use of recovery assays for this purpose is controversial $(184,198)$. Serial serum antithyroglobulin antibody measurements may serve as an imprecise surrogate marker of residual normal thyroid tissue or tumor $(198,199)$. Serum thyroglobulin measurements are less sensitive in patients with small cervical lymph node metastases or less differentiated tumor $(184,200)$. A rising unstimulated or stimulated serum thyroglobulin may indicate disease that is likely to become clinically apparent $(201,202)$.

R43. Serum thyroglobulin should be measured every 6-12 months by an immunometric assay, ideally in the same laboratory and using the same assay, during follow-up of patients with differentiated thyroid carcinoma who have undergone total or near-total thyroidectomy and thyroid remnant ablation. Thyroglobulin antibodies should be quantitatively assessed with every measurement of serum thyroglobulin-Recommendation A

R44. Periodic serum thyroglobulin measurements should be considered during follow-up of patients with differentiated thyroid carcinoma who have undergone less than total thyroidectomy, and in patients who have had a total thyroidectomy but not radioiodine ablation. The cutoff levels to detect tumor during TSH suppression or stimulation are not known, but unstimulated or stimulated levels greater than 2 $\mathrm{ng} / \mathrm{mL}$ that increase over time may represent recurrent disease-Recommendation $\mathrm{C}$

R45. In low risk patients who have had remnant ablation and negative cervical ultrasound and TSH-suppressed thyroglobulin 6 months after treatment, serum thyroglobulin should be measured after thyroxine withdrawal or rhTSH stimulation approximately 12 months after the ablation to verify absence of disease. The timing or necessity of subsequent stimulated testing is uncertain for those found to be free of disease-Recommendation A

\section{What are the roles of diagnostic whole-body radioiodine scans, ultrasound, and other imaging techniques during follow-up of differentiated thyroid cancer?}

Diagnostic whole-body radioiodine scans. There are two main issues that affect the use of diagnostic whole body radioiodine scans (DxWBS) during follow-up: stunning (described above) and accuracy. A DxWBS is most useful during follow-up when there is little or no remaining normal thyroid tissue. Disease not visualized on the DxWBS, regardless of the activity of ${ }^{131}$ I used, may occasionally be visualized on the RxWBS images done after larger, therapeutic amounts of ${ }^{131} \mathrm{I}(186,203-206)$. After radioiodine ablation, subsequent DxWBS have low sensitivity and are usually not necessary in low-risk patients who are clinically free of residual tumor and have an undetectable serum thyroglobulin level during thyroid hormone suppression of serum TSH and negative cervical ultrasound $(177,183,186,205,207)$.

R46. After the first RxWBS performed after radioiodine remnant ablation, low-risk patients with negative TSH-stimulated thyroglobulin and cervical ultrasound do not require routine DxWBS during follow-up-Recommendation A 


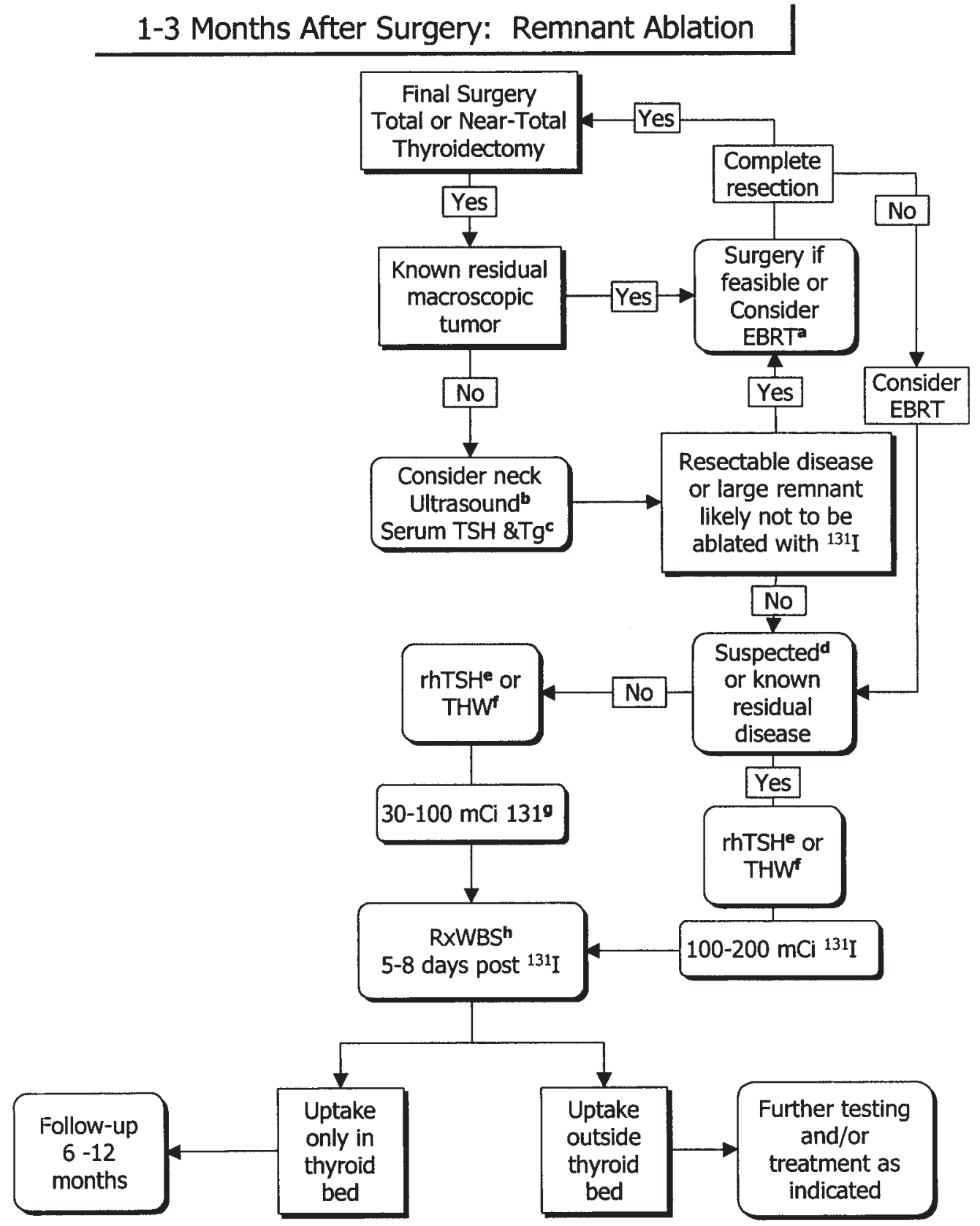

FIG. 2. Algorithm for initial follow-up of patients with differentiated thyroid carcinoma. ${ }^{\text {EEBRT }}$ is external beam radiotherapy. The usual indication for EBRT is macroscopic unresectable tumor in a patient older than 45 years. ${ }^{b} \mathrm{Neck}$ ultrasonography of operated cervical compartments is often compromised for several months after surgery. ${ }^{\mathrm{C}} \mathrm{Tg}$ is thyroglobulin with antithyroglobulin antibody measurement; serum Tg is usually measured by immunometric assay and may be falsely elevated for several weeks by injury from surgery or by heterophile antibodies, although a very high serum Tg level after surgery usually indicates residual disease. ${ }^{\mathrm{d} S o m e}$ clinicians suspect residual disease when malignant lymph nodes, or tumors with aggressive histologies (as defined in the text) have been resected, or when there is a microscopically positive margin of resection. erhTSH is recombinant human thyrotropin, which is not Food and Drug Administration (FDA)-approved in the United States for preparing patients for therapy, but was approved in 2005 for remnant ablation in Europe, and is administered as follows: $0.9 \mathrm{mg}$ rhTSH intramuscularly on 2 consecutive days, followed by ${ }^{131} \mathrm{I}$ therapy on third day. ${ }^{\mathrm{f}} \mathrm{THW}$ is levothyroxine and/or triiodothyronine withdrawal. gSee text for exceptions regarding remnant ablation. DxWBS (diagnostic whole body scintigraphy) is not usually necessary at this point, but may be performed if the outcome will change the decision to treat with radioiodine and/or the amount of administered activity. hRxWBS is posttreatment whole-body scan done 5 to 8 days after therapeutic ${ }^{131}$ I administration. (Modified from J Nucl Med, 46:1079-1088, 2005. Reprinted with permission.) 


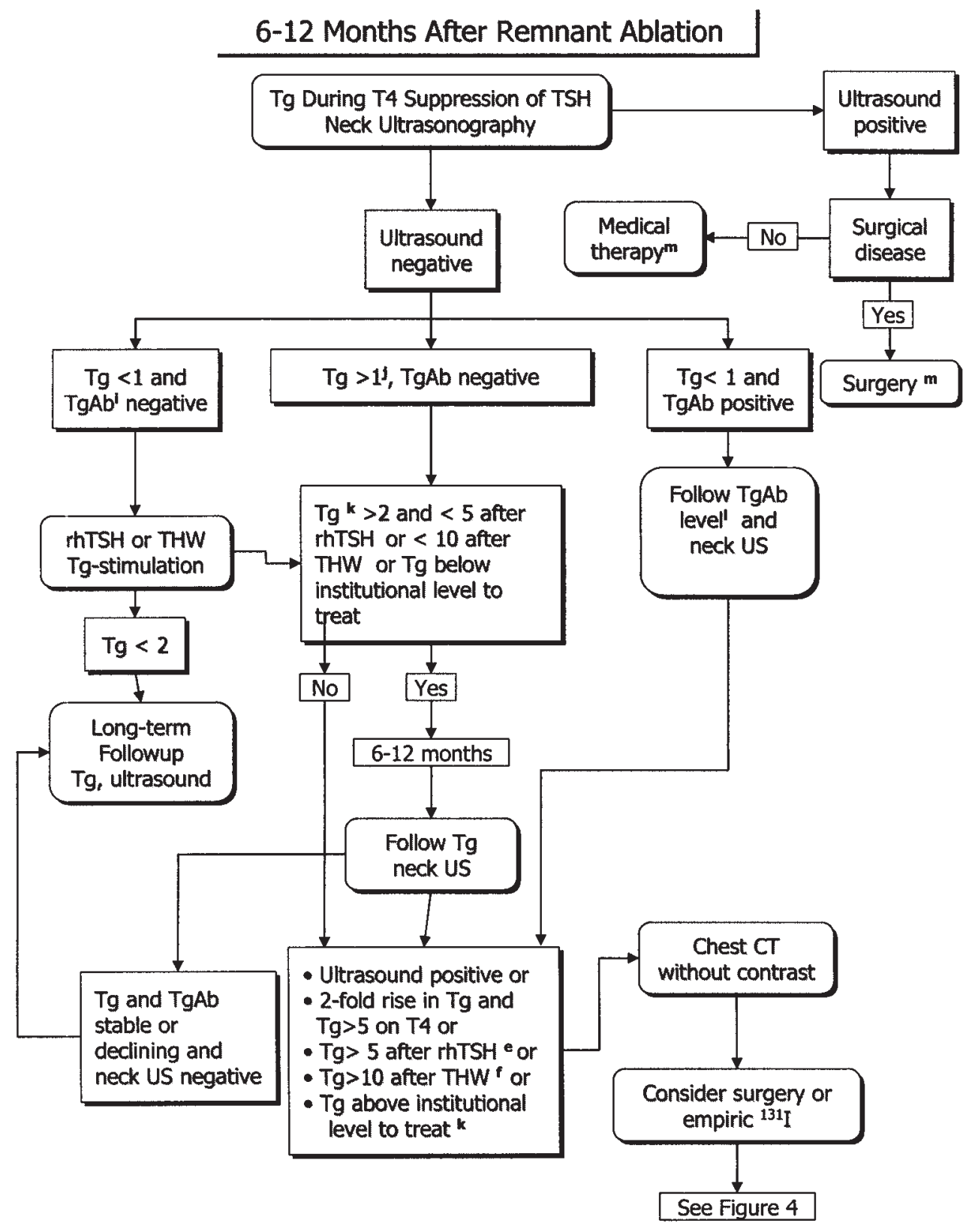

FIG. 3. Longer term follow-up of patients with differentiated thyroid carcinoma. ${ }^{\mathrm{i}} \mathrm{TgAb}$ is antithyroglobulin antibody usually measured by immunometric assay. jHeterophile antibodies may be a cause of falsely elevated serum Tg levels. (Preissner CM, Dodge LA, O'Kane DJ, Singh RJ, Grebe SK 2005 Prevalence of heterophilic antibody interference in eight automated tumor marker immunoassays. Clin Chem 51:208-210; Preissner CM, O'Kane DJ, Singh RJ, Morris JC, Grebe SK 2003 Phantoms in the assay tube: heterophile antibody interferences in serum thyroglobulin assays. J Clin Endocrinol Metab 88:3069-3074.) The use of heterophile blocking tubes or heterophile blocking reagents have reduced, but not completely eliminated this problem. Tg that rises with thyrotropin (TSH) stimulation and falls with TSH suppression is unlikely to result from heterophile antibodies. ${ }^{~}$ See text concerning further information regarding levels of Tg at which therapy should be considered. ${ }^{1} \mathrm{Tg}$ radioimmunoassay (RIA) may be falsely elevated or suppressed by TgAb. Tg results following TSH stimulation with recombinant human thyrotropin (rhTSH) or thyroid hormone withdrawal are invalidated by $\mathrm{TgAb}$ in the serum even when $\mathrm{Tg}$ is measured by most RIA tests. TgAb levels often decline to undetectable levels over years following surgery (Chiovato L, Latrofa F, Braverman LE, Pacini F, Capezzone M, Masserini L, Grasso L, Pinchera A 2003 Disappearance of humoral thyroid autoimmunity after complete removal of thyroid antigens. Ann Intern Med 139:346-351). A rising level of $\mathrm{TgAb}$ may an early indication of recurrent disease (Spencer CA, Takeuchi M, Kazarosyan M, Wang CC, Guttler RB, Singer PA, Fatemi S, LoPresti JS, Nicoloff JT 1998 Serum thyroglobulin autoantibodies: prevalence, influence on serum thyroglobulin measurement, and prognostic significance in patients with differentiated thyroid carcinoma. J Clin Endocrinol Metab 83:1121-1127). mSee text for decision regarding surgery versus medical therapy, and surgical approaches to locoregional metastases. Fine-needle aspiration confirmation of malignancy is generally advised. Preoperative chest computed tomography (CT) is recommended as distant metastases may change management. (Modified from J Nucl Med, 46:1079-1088, 2005. Reprinted with permission.) 
R47. DxWBS 6-12 months after remnant ablation may be of value in the follow-up of patients with high or intermediate risk of persistent disease, but should be done with low dose ${ }^{131}$ I or ${ }^{123}$ I-Recommendation C

Cervical ultrasonography. Cervical ultrasonography is highly sensitive in the detection of cervical metastases in patients with differentiated thyroid cancer (208). Cervical metastases occasionally may be detected by neck ultrasonography even when TSH-stimulated serum thyroglobulin levels remain undetectable (200).

R48. After surgery, cervical ultrasound to evaluate the thyroid bed and central and lateral cervical nodal compartments should be performed at 6 and 12 months and then annually for at least 3-5 years, depending on the patients' risk for recurrent disease and thyroglobulin status-Recommendation B

\section{What is the role of thyroxine suppression in long-term follow-up of differentiated thyroid cancer?}

A meta-analysis has suggested an association (168) between thyroid hormone suppression therapy and reduction of major adverse clinical events. The appropriate degree of TSH suppression by $\mathrm{LT}_{4}$ is still unknown. One study found that a constantly suppressed TSH $(\leq 0.05 \mu \mathrm{U} / \mathrm{mL})$ was associated with a longer relapse-free survival than when serum TSH levels were always $1 \mu \mathrm{U} / \mathrm{mL}$ or greater, and that the degree of TSH suppression was an independent predictor of recurrence in multivariate analysis (169). Conversely, another large study found that disease stage, patient age, and ${ }^{131}$ I therapy independently predicted disease progression, but that the degree of TSH suppression did not (73). A third study showed that during $\mathrm{LT}_{4}$ therapy the mean thyroglobulin levels were significantly higher when TSH levels were normal than when TSH levels were suppressed $(<0.5$ $\mathrm{mU} / \mathrm{L}$ ) but only in patients with local or distant relapse (209).

R49. In patients with persistent disease, the serum TSH should be maintained below $0.1 \mathrm{mU} / \mathrm{L}$ indefinitely in the absence of specific contraindications-Recommendation B

R50. In patients who are clinically free of disease but who presented with high risk disease, consideration should be given to maintaining TSH suppressive therapy to achieve serum TSH levels of 0.1 to $0.5 \mathrm{mU} / \mathrm{L}$ for 5-10 years-Recommendation $\mathrm{C}$

R51. In patients free of disease, especially those at low risk for recurrence, the TSH may be kept within the low normal range ( 0.3 to $2 \mathrm{mU} / \mathrm{L})$ - Recommendation $\mathrm{C}$

\section{What is the most appropriate management of patients with metastatic disease?}

Metastases discovered during follow-up are likely manifestations of persistent disease that has survived initial treatment, and are often incurable by additional ${ }^{131}$ I treatment. Some patients will have a reduction in tumor burden with additional treatments that may offer a survival or palliative benefit $(204,210-212)$.

The preferred hierarchy of treatment for metastatic dis- ease (in order) is surgical excision of locoregional disease in potentially curable patients, ${ }^{131}$ I therapy, external beam radiation, watchful waiting with patients with stable asymptomatic disease, and experimental chemotherapy trials. Experimental trials may be tried before external beam radiation in special circumstances, in part because of the morbidity of external beam radiation and its relative lack of efficacy. A small fraction of patients may benefit from radiofrequency ablation (213), ethanol ablation (214), or chemoembolization (215).

Surgical management of locoregional metastases. Surgery is favored for locoregional (i.e., cervical lymph nodes and/or soft tissue tumor in the neck) recurrences, when distant metastases are not present. Approximately one third to one half of patients may become free of disease in short-term follow-up (216). It is not clear that treatment of locoregional disease is beneficial in the setting of untreatable distant metastases, except for possible palliation of symptoms or prevention of airway or aero-digestive obstruction. Impalpable metastatic lymph nodes, visualized on ultrasound or other anatomic imaging modality, have survived initial ${ }^{131} \mathrm{I}$ therapy and should be considered for resection. Most surgeons endorse complete ipsilateral compartmental dissection of involved compartments with persistent/recurrent disease while sparing vital structures (e.g., ipsilateral central neck dissection [level VI], or modified neck dissection [levels II-V sparing the spinal accessory nerve, the internal jugular vein, and sternocleidomastoid muscle]) (217) as opposed to berry picking or selective lymph node resection procedures or ethanol ablation (214), because microscopic lymph node metastases are commonly more extensive than would appear from imaging studies alone $(112,218,219)$.

R52. Patients with persistent/recurrent disease confined to the neck should undergo complete ipsilateral or central compartmental dissection of involved compartments while sparing vital structures-Recommendation B

Surgical management of aero-digestive invasion. For tumors that invade the upper aero-digestive tract, surgery combined with additional therapy such as ${ }^{131} \mathrm{I}$ and/or external beam radiation is generally advised $(220,221)$. Patient outcome is related to complete resection of all gross disease with the preservation of function, with techniques ranging from shaving tumor off the trachea or esophagus for superficial invasion, to more aggressive techniques when the trachea is more deeply invaded (e.g., direct intraluminal invasion) including tracheal resection and anastomosis (222-224) or esophagopharyngectomy. Patients who are not curable may undergo less aggressive local treatment. Tracheal stents and tracheotomy can improve quality of life. Laser therapy is indicated in cases of asphyxia or significant hemoptysis and as a preliminary step prior to subsequent radical or palliative treatments (221).

R53. When technically feasible, surgery for aero-digestive disease is recommended in combination with radioiodine and/or external beam radiotherapy-Recommendation B

Radioiodine therapy for locoregional or distant metastatic disease. For regional nodal metastases discovered on 
DxWBS, radioiodine is usually used, although surgery is typically used in the presence of bulky disease or disease amenable to surgery found on anatomic imaging such as ultrasound, CT scanning or MRI. Radioiodine is also used adjunctively after surgery for regional nodal disease or aerodigestive invasion if residual disease is present or suspected.

Methods of administering ${ }^{131}$ I for locoregional or metastatic disease. Despite the apparent effectiveness of ${ }^{131} \mathrm{I}$ therapy in many patients, the optimal therapeutic activity remains uncertain and controversial (225). There are three approaches to ${ }^{131} \mathrm{I}$ therapy: empiric fixed amounts, therapy determined by the upper bound limit of blood and body dosimetry, and quantitative tumor dosimetry (226). Dosimetric methods are often reserved for patients with distant metastases or unusual situations such as renal failure or when therapy with rhTSH stimulation is deemed necessary. Comparison of outcome among these methods from published series is difficult (227). No prospective randomized trial to address the optimal therapeutic approach has been published. Arguments in favor of higher activities cite a positive relationship between the total ${ }^{131}$ I uptake per tumor mass and outcome (141), while others have not confirmed this relationship $(227,228)$.

R54. In the treatment of locoregional or metastatic disease, no recommendation can be made about the superiority of one method of radioiodine administration over another (empiric high dose versus blood or body dosimetry)—Recommendation I

rhTSH in the management of recurrent or metastatic disease. No randomized trial comparing thyroid hormone withdrawal therapy to rhTSH-mediated therapy has been reported, despite a growing body of nonrandomized studies regarding this use (229-237). The use of rhTSH does not eliminate and may even increase the possibility of rapid swelling of metastatic lesions $(234,238-240)$. Many of these case reports and series report disease stabilization or improvement in some patients after rhTSH-mediated ${ }^{131}$ I therapy.

R55. There are currently insufficient outcome data to recommend rhTSH-mediated therapy for all patients with metastatic disease being treated with ${ }^{131} \mathrm{I}$-Recommendation D

R56. rhTSH-mediated therapy may be indicated in selected patients with underlying comorbidities making iatrogenic hypothyroidism potentially risky, in patients with pituitary disease who are unable to raise their serum TSH, or in patients in whom a delay in therapy might be deleteriousRecommendation C

The use of lithium in ${ }^{131}$ I therapy. Lithium inhibits iodine release from the thyroid without impairing iodine uptake, thus enhancing ${ }^{131}$ I retention in normal thyroid and tumor cells (241). One study (242) found that lithium increased the estimated ${ }^{131}$ I radiation dose in metastatic tumors an average of more than twofold, but primarily in those tumors that rapidly cleared iodine (242).

R57. Because there are no outcome data that demonstrate a better outcome of patients treated with ${ }^{131} \mathrm{I}$ in the setting of lithium therapy, the committee cannot recommend for or against its use-Recommendation I

Treatment of distant metastatic disease. The overall approach to treatment of distant metastatic thyroid cancer is based upon the following observations and oncologic principles:

1. Morbidity and mortality are increased in patients with distant metastases, but individual prognosis depends upon factors including distribution and number of sites of metastasis (e.g., brain, bone, lung), tumor burden, and age at diagnosis of metastases $(212,237,243-249)$.

2. Improved survival is associated with responsiveness to surgery and/or radioiodine $(212,237,243-249)$.

3 . In the absence of demonstrated survival benefit, certain interventions can provide significant palliation or reduce morbidity $(216,250-252)$.

4. In the absence of improved survival, palliative benefit or reduced potential morbidity, the value of empiric therapeutic intervention is significantly limited by the potential for toxicity.

5. Treatment of a specific metastatic area must be considered in light of the patient's performance status and other sites of disease (e.g., 5\%-20\% of patients with distant metastases die from progressive cervical disease $(249,253)$.

6. Longitudinal reevaluation of patient status and continuing reassessment of potential benefit and risk of intervention is required.

7. The overall poor outcome of patients with radiographically evident or symptomatic metastases that do not respond to radioiodine, the complexity of multidisciplinary treatment considerations and the availability of prospective clinical trials should encourage the clinician to refer such patients to tertiary centers with particular expertise.

Treatment of pulmonary metastases. In the management of the patient with pulmonary metastases, key criteria for therapeutic decisions include size of metastatic lesions (macronodular typically detected by chest radiography; micronodular typically detected by CT; lesions beneath the resolution of CT); avidity for radioiodine and, if applicable, response to prior radioiodine therapy; and stability (or lack thereof) of metastatic lesions. Pulmonary pneumonitis and fibrosis are rare complications of high dose radioactive iodine treatment. Dosimetry studies with a limit of $80 \mathrm{mCi}$ whole-body retention at 48 hours and 200 cGy to the red bone marrow should be considered in patients with diffuse ${ }^{131}$ I pulmonary uptake (254). If pulmonary fibrosis is suspected, then appropriate periodic pulmonary function testing and consultation should be obtained. The presence of pulmonary fibrosis may limit the ability to further treat metastatic disease with radioiodine.

R58. Pulmonary micrometastases should be treated with radioiodine therapy, repeated every 6-12 months as long as disease continues to respond, as the highest rates of complete remission are reported in these subgroups $(243,248,255)$ - Recommendation A

R59. The selection of radioiodine activity to administer for pulmonary micrometastases can be empiric (100-300 mCi) 
or estimated by dosimetry to limit whole body retention to $80 \mathrm{mCi}$ at 48 hours and $200 \mathrm{cGy}$ to the red bone marrowRecommendation C

Macronodular pulmonary metastases may also be treated with radioiodine if demonstrated to be iodine avid. How many doses of radioiodine to give and how often to give it is a decision that must be individualized based on the disease response to treatment, the rate of disease progression in between treatments, age of the patient, size of the lesion, and presence/absence of other metastatic lesions and the availability of other treatment options including clinical trials $(243,248)$

R60. Radioiodine-avid macronodular metastases should be treated with radioiodine, and treatment repeated when objective benefit is demonstrated (decrease in the size of the lesions, decreasing thyroglobulin), but complete remission is not common and survival remains poor. The selection of radioiodine activity to administer can be made empirically (100-300 mCi) or estimated by dosimetry to limit whole body retention to $80 \mathrm{mCi}$ at 48 hours and $200 \mathrm{cGy}$ to the red bone marrow-Recommendation B

Nonradioiodine avid pulmonary disease. In one study, administration of $200-300 \mathrm{mCi}$ of radioiodine to 10 patients with pulmonary macrometastases who had negative $3 \mathrm{mCi}$ diagnostic scans was associated with a fivefold increase in the median TSH-suppressed thyroglobulin, and death was reported in several patients within 4 years of treatment (256). Although not specifically limited to pulmonary lesions, patients with increasing volumes of 18-fluorodeoxyglucose (FDG)-avid disease seen on positron-emission tomograpy (PET) scans were less likely to respond to radioiodine and more likely to die during a 3-year follow-up compared with FDG-negative patients (257). One study found that radioiodine therapy of metastatic lesions that were positive on FDGPET scanning was of no benefit (258). In other studies of FDG-PET imaging, however, insufficient details exist in patients known to have pulmonary metastases to assess the utility of this modality to predict treatment response or prognosis (259). Traditional cytotoxic chemotherapeutic agents such as doxorubicin and cisplatin, are generally associated with no more than $25 \%$ partial response rates, and complete remission has been rare (260).

R61. Evidence of benefit of routine treatment of nonradioiodine avid pulmonary metastases is insufficient to recommend any specific systemic therapy-Recommendation I

R62. For many patients, metastatic disease is slowly progressive and patients can often be followed conservatively on TSH-suppressive therapy with minimal evidence of radiographic or symptomatic progression. For selected patients, however, other treatment options need to be considered, such as metastasectomy, endobronchial laser ablation, or external beam radiation for palliation of symptomatic intrathoracic lesions (e.g., obstructing or bleeding endobronchial masses), and pleural or pericardial drainage for symptomatic effusions. Referral for participation in clinical trials should be considered-Recommendation C
Treatment of bone metastases. In the management of the patient with bone metastases, key criteria for therapeutic decisions include risk for pathologic fracture, particularly in a weight-bearing structure; risk for neurologic compromise from vertebral lesions; presence of pain; avidity of radioiodine uptake; and potential significant marrow exposure from radiation arising from radioiodine-avid pelvic metastases.

R63. Complete surgical resection of isolated symptomatic metastases has been associated with improved survival and should be considered, especially in patients less than 45 years old $(212,246)$ - Recommendation B

R64. Radioiodine therapy of iodine-avid bone metastases has been associated with improved survival and should be used $(212,248)$. The radioiodine activity administered can be given empirically (150-300 mCi) or estimated by dosimetry (140)Recommendation B

R65. When skeletal metastatic lesions arise in locations where acute swelling may produce severe pain, fracture, or neurologic complications, external radiation and the concomitant use of glucocorticoids to minimize potential TSH-induced and/or radiation related tumor expansion should be strongly considered (261)—Recommendation C

R66. Painful lesions that cannot be resected can also be treated by several options individually or in combination, including: radioiodine, external beam radiotherapy; intra-arterial embolization $(215,262)$, radiofrequency ablation $(263)$, periodic pamidronate or zoledronate infusions (with monitoring for development of possible osteonecrosis) (252), or bone-seeking radiopharmaceuticals such as strontium-89 or samarium-153 (264). While many of these modalities have been shown to relieve bone pain in cancer, they have not necessarily been reported to have been used in patients with thyroid cancer-Recommendation $\mathrm{C}$

R67. Evidence is insufficient to recommend treatment of asymptomatic, non-radioiodine responsive, stable lesions that do not threaten nearby critical structures-Recommendation I

Treatment of brain metastases. Brain metastases typically occur in older patients with more advanced disease at presentation, and are associated with a poor prognosis (237). Surgical resection and external beam radiotherapy traditionally have been the mainstays of therapy $(237,265)$. There are few data showing efficacy of radioiodine.

R68. Complete surgical resection of central nervous system (CNS) metastases should be considered regardless of radioiodine avidity, as it is associated with significantly longer survival-Recommendation B

R69. CNS lesions that are not amenable to surgery should be considered for external beam irradiation. Often very targeted approaches (such as radiosurgery) are employed to limit the radiation exposure of the surrounding brain tissue. Wholebrain and spine irradiation could be considered if multiple metastases are present-Recommendation C 
R70. If CNS metastases do concentrate radioiodine, then radioiodine could be considered. If radioiodine is being considered, prior external beam radiotherapy and concomitant glucocorticoid therapy are strongly recommended to minimize the effects of a potential TSH-induced increase in tumor size and the subsequent inflammatory effects of the radioiodine (261)—Recommendation C

Management of complications of radioiodine therapy. While radioiodine appears to be a reasonably safe therapy, it is associated with a cumulative dose-related low risk of early and late onset complications such as salivary gland damage, nasolacrimal duct obstruction (268), and secondary malignancies (267). Therefore, it is important to ensure that the benefits of repeated radioiodine therapy outweigh the potential risks. There is probably no dose of radioactive iodine that is completely safe nor is there any maximum cumulative dose that could not be used in selected situations. However, with higher individual and cumulative doses there are increased risks of side effects as discussed previously.

R71. For acute transient loss of taste or change in taste and sialadenitis, some have recommended measures to prevent damage to the salivary glands including amifostine, hydration, sour candies and cholinergic agents (268), but evidence is insufficient to recommend for or against these modalities. One recent study suggested sour candy may actually increase salivary gland damage when given within 1 hour of radioiodine therapy, compared to its use until 24 hours posttherapy (269). For chronic salivary gland complications, such as dry mouth and dental caries, cholinergic agents may increase salivary flow (268)-Recommendation I

R72. Patients with xerostomia are at increased risk of dental caries and should discuss preventative strategies with their dentists-Recommendation C

R73. Surgical correction should be considered for nasolacrimal outflow obstruction, which often presents as excessive tearing (epiphora) but also predisposes to infectionRecommendation B

Second malignancies and leukemia from radioiodine therapy. Long-term follow-up studies demonstrate a very low risk of secondary malignancies (bone and soft tissue malignancies, colorectal cancer, salivary tumors, and leukemia) in long-term survivors (267). The risk of secondary malignancies is dose-related (267). There appears to be an increased risk of breast cancer in women with thyroid cancer (270). It is unclear whether this is the result of screening bias, radioiodine therapy, or other factors.

R74. Because there is no evidence demonstrating a benefit of more intensive screening, all patients with thyroid cancer should be encouraged to seek age-appropriate screenings for cancer according to routine health maintenance recommendations-Recommendation C

Other risks to the bone marrow from radioiodine therapy. Published data indicate that when administered activities are selected to remain below 200 cGy to the bone marrow, minimal transient effects are noted in white blood cell (WBC) and platelet counts (254). However, persistent mild decre- ments in white blood count and/or platelets are not uncommon in patients who have received multiple radioiodine therapies. Furthermore, radiation to the bone marrow is impacted by several factors, including renal function.

R75. Patients receiving therapeutic doses of radioiodine should have baseline complete blood cell (CBC), platelet count and assessment of renal function-Recommendation $\mathrm{C}$

Effects of radioiodine on gonadal function and in breastfeeding women. Gonadal tissue is exposed to radiation from radioiodine in the blood, urine and feces. Temporary amenorrhea/oligomenorrhea lasting 4-10 months occurs in $20 \%-27 \%$ of menstruating women after ${ }^{131}$ I therapy for thyroid cancer. Although the numbers of patients studied are small, long-term rates of infertility, miscarriage, and fetal malformation do not appear to be elevated in women after radioiodine therapy $(271,272)$. One large retrospective study suggested that pregnancy should be postponed for 1 year after therapy because of an increase in miscarriage rate (273). Ovarian damage from radioiodine therapy may result in menopause occurring approximately 1 year earlier than the general population, but this result was not associated with cumulative dose administered or the age at which the therapy was given (274). In men, radioiodine therapy may be associated with a temporary reduction in sperm counts and elevated serum follicle-stimulating hormone (FSH) levels $(275,276)$. Higher cumulative doses $(500-800 \mathrm{mCi})$ in men are associated with an increased risk of persistent elevation of serum FSH levels, but fertility and risks of miscarriage or congenital abnormalities in subsequent pregnancies are not changed with moderate radioiodine doses (approximately $200 \mathrm{mCi})(277,278)$. Permanent male infertility is unlikely with a single ablative dose of radioiodine, but theoretically there could be cumulative damage with multiple treatments. It has been suggested that sperm banking be considered in men who may receive cumulative radioiodine doses $400 \mathrm{mCi}$ or more (278). Gonadal radiation exposure is reduced with good hydration, frequent micturition to empty the bladder and avoidance of constipation (279).

R76. Women receiving radioactive iodine therapy should avoid pregnancy for 6-12 months-Recommendation B

R77. Radioactive iodine should not be given to breast-feeding women. Depending on the clinical situation, radioiodine therapy could be deferred until a time when lactating women have stopped breast-feeding for at least 6-8 weeks. Dopaminergic agents might be useful in decreasing breast exposure, although caution should be exercised given the risk of serious side-effects associated with their routine use to suppress postpartum lactation-Recommendation B

\section{How should thyroglobulin-positive patients be managed?}

If the unstimulated thyroglobulin is or becomes detectable or stimulated thyroglobulin levels rise to greater than $2 \mathrm{ng} / \mathrm{mL}$, imaging of the neck and chest should be performed to search for metastatic disease, typically with neck ultrasound and with thin-cut $(5-7 \mathrm{~mm})$ helical chest CT. Iodinated contrast should be avoided if radioiodine therapy is planned within the subsequent few months, although intravenous contrast may aid 


\section{2 or more Months After Remnant Ablation}

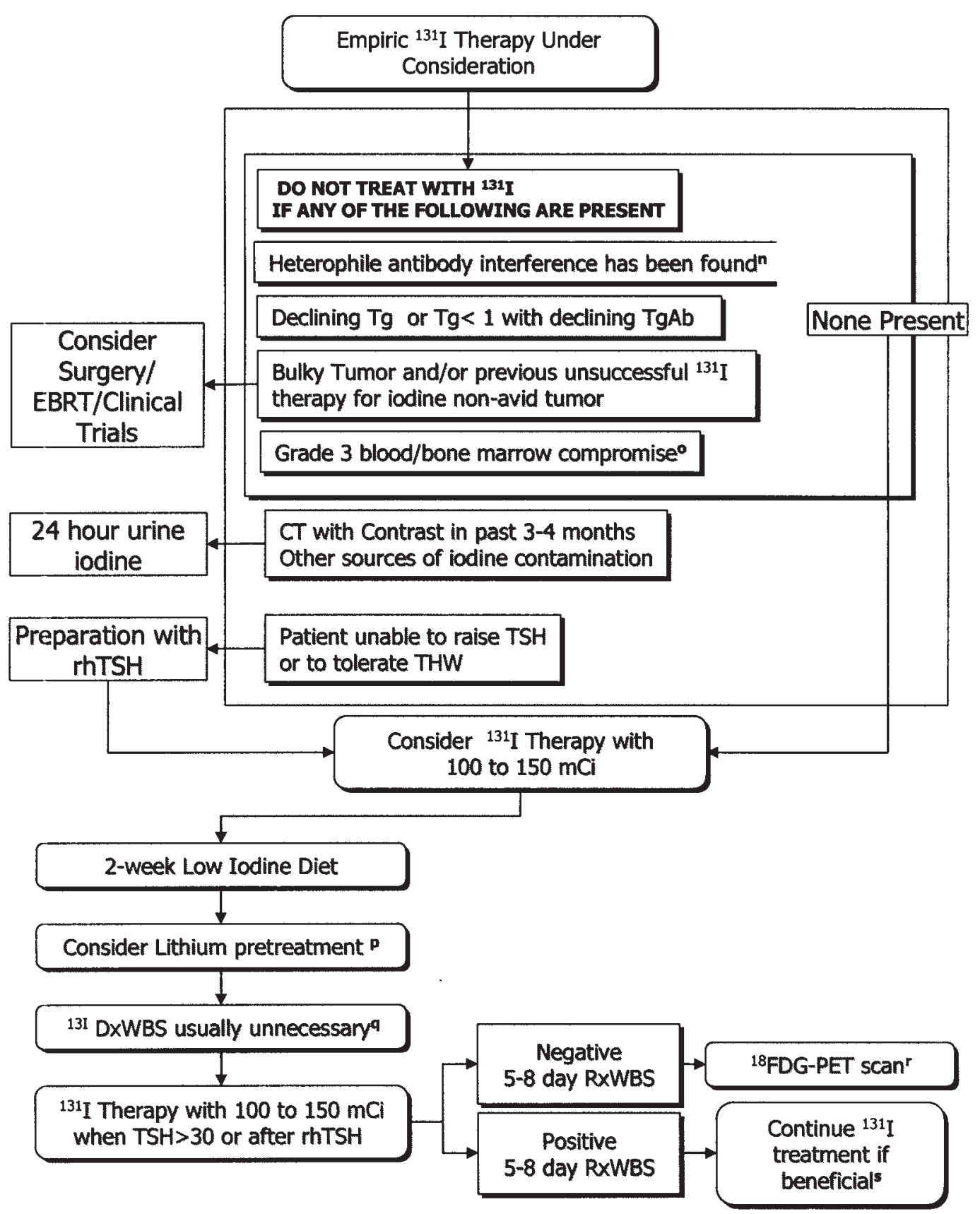

FIG. 4. Considerations for empiric treatment with radioiodine. ${ }^{\mathrm{n}}$ Thyroglobulin $(\mathrm{Tg})$ that rises with thyrotropin (TSH) stimulation and falls with TSH suppression is unlikely to result from heterophile antibodies. ${ }^{\circ}$ National Cancer Institute Common Terminology Criteria for Adverse Events, Version 3.0, (www.ctep.cancer.gov). PLithium may be beneficial at this point but there are few clinical studies. ${ }^{2}$ DxWBS is diagnostic whole-body scintigraphy. ${ }^{\mathrm{r}} \mathrm{FDG}-\mathrm{PET}$ scanning sensitivity and specificity may be enhanced with stimulation (rhTSH or THW) and by fusion with CT imaging (PET/CT). ${ }^{\mathrm{s} D o s i m e t r y ~ c o u l d ~ b e}$ considered to allow administration of maximum radioiodine activity if the tumor is life-threatening. (Reprinted with permission from J Nucl Med 46:1079-1088, 2005.)

in identification of mediastinal disease. If imaging is negative for disease that is potentially curable by surgery, then empiric therapy with radioiodine $(100-200 \mathrm{mCi})$ should be considered to aid localization or for therapy of surgically incurable disease (Fig. 4). This approach may identify the location of persistent disease in approximately $50 \%$ of patients $(203,280)$ with a wide range of reported success. Some investigators have reported a decrease in serum thyroglobulin after empiric radioiodine therapy in patients with negative RxWBS $(281,282)$, but there is no evidence for improved survival with empiric therapy in this setting $(258,283)$. On the other hand, serum thyroglobulin levels may decline without specific therapy (282). 
A cutoff value of thyroglobulin above which a patient should be treated with an empiric dose of radioiodine is difficult to determine, in part because of the wide variation in available thyroglobulin assays (including those used in reports suggesting benefit of such therapy) and the differences in thyroglobulin levels based on method and degree of TSH stimulation or suppression. Recent studies have reported primarily on patients with thyroglobulin levels after thyroxine withdrawal of $10 \mathrm{ng} / \mathrm{mL}$ or higher, and it has been suggested that a corresponding level after rTSH stimulation would be $5 \mathrm{ng} / \mathrm{mL}(204,256,280,282,283)$. A thyroglobulin level that is rising may warrant greater concern for the need for empiric therapy, although data regarding the appropriate rate of change are minimal (202).

R78. Empiric radioactive iodine therapy (100-200 mCi) might be considered in patients with elevated or rising serum thyroglobulin levels in whom imaging has failed to reveal a potential tumor source-Recommendation C

R79. If persistent nonresectable disease is localized after an empiric dose of radioiodine, and there is objective evidence of significant tumor reduction, then radioiodine therapy should be repeated until the tumor has been eradicated or the tumor no longer responds to treatment. The risk of repeated therapeutic does of radioiodine must be balanced against uncertain long-term benefits-Recommendation C

Patients with a negative posttreatment whole-body scan (RxWBS)

R80. If an empiric dose (100-200 mCi) of radioiodine fails to localize the persistent disease, ${ }^{18}$ FDG-PET scanning should be considered, especially in patients with unstimulated serum thyroglobulin levels more than $10-20 \mathrm{ng} / \mathrm{ml}$, in order to localize metastatic lesions that may require treatment or continued close observation $(284,285)$ - Recommendation B

Stimulation with endogenous TSH after thyroxine withdrawal or rhTSH (286) and CT fusion (287) may enhance the sensitivity and specificity of FDG-PET scanning.

R81. Thyroglobulin positive, RxWBS-negative patients with disease that is incurable with surgery and is structurally evident or visualized on FDG-PET scan can be managed with thyroid hormone suppression therapy, external beam radiotherapy, chemotherapy, radiofrequency ablation, chemoembolization, or monitoring without additional therapy if stable. Clinical trials should also be considered-Recommendation C

R82. Thyroglobulin-positive, RxWBS-negative patients with no structural evidence of disease can be followed with serial structural imaging studies and serial thyroglobulin measurements, with both performed more frequently if the thyroglobulin level is rising. When and how often to repeat FDG-PET imaging in this setting is less certain-Recommendation $\mathrm{C}$

\section{What is the role of external beam radiotherapy in treatment of metastatic disease?}

R83. External beam radiation should be used in the management of unresectable gross residual cervical disease, painful bone metastases, metastatic lesions in critical locations likely to result in fracture, neurological, or compressive symptoms that are not amenable to surgery (e.g., vertebral metastases, CNS metastases, selected mediastinal or subcarinal lymph nodes, pelvic metastases) $(174,226)$ - Recommendation $\mathrm{B}$

\section{What is the role of chemotherapy in the treatment of metastatic disease?}

Studies of chemotherapy for advanced, radioiodine-resistant differentiated thyroid carcinoma are limited. Doxorubicin monotherapy may be effective in up to $40 \%$ of patients (most partial response or stable disease) when dosed appropriately (60-75 mg/m² every 3 weeks) (288-291) but durable responses are uncommon. Most studies of combination chemotherapy show no increased response over single agent doxorubicin and increased toxicity (292). Some specialists recommend consideration of single agent doxorubicin or paclitaxel, or a combination of these agents based on limited data in anaplastic thyroid carcinoma (293). One recent study evaluated the effect of combination chemotherapy (carboplatinum and epirubicin) under TSH stimulation (endogenous or rhTSH) (294), demonstrating an overall rate of complete and partial response of $37 \%$. These data need to be confirmed prior to consideration for general use.

R84. Chemotherapy has modest benefit in patients with advanced, radioiodine-resistant thyroid cancer. Patients with progressive disease should first be considered for clinical trials. If clinical trials are unavailable or the patient prefers standard cytotoxic chemotherapy, doxorubicin used as a single agent or in combination with other agents may be considered-Recommendation C

\section{Should patients skip chemotherapy and instead opt for clinical trials?}

If the patient qualifies for a clinical trial, they should consider bypassing traditional chemotherapy and moving directly to clinical trials. However, patients often cannot participate in clinical trials because of the time and expense required, or failure to meet strict eligibility criteria. Most available trials can be found listed at www.clinicaltrials. gov; www.nci.nih.gov; www.centerwatch.com; or www.thyroid.org

R85. Patients with advanced, progressive, unresectable radioiodine non-responsive thyroid cancer who are being considered for chemotherapy should be considered for entry into clinical trials-Recommendation C

\section{What Are the Directions for Future Research?}

\section{Novel therapies and clinical trials}

While surgery and the judicious use of radioactive iodine, as described in these guidelines, is sufficient treatment for the majority of patients with differentiated thyroid cancer, a minority of these patients experiences progressive, lifethreatening growth and metastatic spread of the disease. For these individuals, experimental treatments may be considered. Several clinical trials are already in progress; others are at various stages of development and the number of available clinical trials is likely to grow rapidly. The recent ex- 
plosion of knowledge regarding the molecular and cellular pathogenesis of cancer has led to the development of a range of targeted therapies, now beginning clinical evaluation. These therapies can be grouped into a number of categories:

Oncogene inhibitors. Tyrosine kinase inhibitors target the activated RET/PTC oncogene, responsible for a proportion of PTC. Inhibitors of RAS, RAF, and MEK kinase target various members of the same signaling pathway. Several of these agents are in development, with at least one clinical trial underway. Specific oncogene targeting for follicular thyroid cancer and Hürthle thyroid cancer awaits better understanding of the pathways involved in initiation of these tumor types.

Modulators of growth or apoptosis. Key components of growth and apoptotic pathways are targeted by PPAR $\gamma$ activators, including COX2 inhibitors; retinoids, which activate PPAR $\gamma /$ RXR heterodimers; Bortezomib (Velcade ${ }^{\circledR}$, Millenium Pharmaceuticals, Cambridge, MA), which inactivates the cancer proteasome; and derivatives of geldanomycin, which target the hsp-90 protein. Clinical trials in thyroid cancer of each of these agents are available.

Angiogenesis inhibitors. Targeting of vascular endothelial growth factor (VEGF) and other members of the signaling cascade responsible for neoangiogenesis may limit the growth of cancers by restricting their blood supply. Trials of several of these agents are currently underway in both anaplastic and differentiated thyroid cancer.

Immunomodulators. Stimulation of the immune response to cancer may be achieved by augmenting the activity of antigen-presenting dendritic cells. This approach has shown possible benefits in phase 1 clinical trials, but has not yet been studied in thyroid cancer. The apparent immunogenicity of thyroid cells makes this an attractive approach for future clinical trials.

Gene therapy. Preclinical studies have demonstrated some efficacy in thyroid cancer cell lines. Approaches include introducing toxic genes under the control of thyroid-specific promoters, or restoration of the p53 tumor-suppressor gene in anaplastic thyroid cancer cell lines. Problems with gene delivery limit the clinical utility of these approaches, which have not yet reached clinical trials in thyroid cancer.

Each of these targeted approaches holds promise for our future ability treat patients with life-threatening disease unresponsive to traditional therapy. In the meantime, for appropriate patients, entry into one of the available clinical trials may be an attractive option.

\section{Better understanding of the long term-risks of radioiodine}

With the more widespread use of radioactive iodine in the management of thyroid cancer, it is imperative that we have a better understanding of the long-term risks associated with its use. Research that focuses on how to minimize the impact of radioiodine on the salivary glands in order to prevent siladenitis and xerostomia would provide a significant benefit to patients. A better understanding of the long-term effects of radioiodine on reproductive issues in men and women is also an important topic. Finally, while the risk of second malignancies appears small following the usual doses of radioiodine used for remnant ablation, we need better understanding of the long-term risks for salivary gland tumors, gastrointestinal tumors, bladder tumors, and colon cancers when repeated doses of radioiodine are needed in young patients with potentially curable thyroid cancer.

\section{Clinical significance of persistent low-level thyroglobulin}

After initial surgery and radioiodine therapy some patients will have persistently detectable stimulated serum thyroglobulin when evaluated 9-12 months later. Most of these patients have stimulated thyroglobulin levels in the range of 1-10 ng/mL, levels typically associated with a small volume of tissue. Some of these patients demonstrate a subsequent spontaneous fall in thyroglobulin over time, others remain stable, while still others demonstrate rising thyroglobulin levels. The optimal management of these patients is unknown. How often should they undergo neck ultrasound or stimulated serum thyroglobulin testing? Which (if any) of these patients undergo chest $\mathrm{CT}, \mathrm{PET}$, or empiric radioiodine therapy? Can we improve our abilities to predict and monitor which patients are likely to be harmed by their disease as opposed to those who will live unaffected by theirs? Does metastatic disease in small local lymph nodes have the potential to metastasize to distant sites during observation while on TSH-suppression therapy? The current impetus to test and treat all of these patients is based on the argument that early diagnosis may lead to early treatment of residual disease when treatment is more likely to be effective, as opposed to less effective treatment when the tumor is more bulky, more extensive, or spread to inoperable locations. However, there is no current proof that aggressive treatment of minimal residual disease improves patient outcome. This is brought into focus by the fact that only about $5 \%$ of PTC patients die of their disease, yet more than one third of PTC patients are likely to have persistent disease based on persistent measurable thyroglobulin to stimulation testing.

\section{The problem of thyroglobulin antibodies}

Antithyroglobulin antibodies are a common clinical problem in patients with differentiated thyroid carcinoma (20\%) (198). The presence of these antibodies usually interferes with serum thyroglobulin measurement and recovery assays do not appear to accurately predict this interference $(198,295)$. Decreasing antibody levels are correlated with "disease-free" status while increasing levels suggest persistent disease $(199,296)$. Measurement of thyroglobulin mRNA in the blood may be a sensitive marker for persistent thyroid cells even in the presence of anti-thyroglobulin antibodies (297-299), but RNA extraction is not well standardized and some studies question the specificity of this marker $(300,301)$. Future studies optimizing thyroglobulin mRNA measurements in blood from DTC patients with antithyroglobulin antibodies, further development of thyroglobulin assays that have limited interference by antithyroglobulin antibodies or methods to clear antithyroglobulin antibodies prior to thyroglobulin measurement are needed to better monitor this challenging subgroup of patients with DTC.

\section{Small cervical lymph node metastases}

The rates of cervical lymph node metastases generally range from about $20 \%-50 \%$ in most large series of differen- 
tiated thyroid carcinoma, with higher rates in children or when mircometastases are considered. The location and number of lymph node metastases is often difficult to identify at before or at the time of surgery, especially micrometastases. Although postoperative ${ }^{131}$ I given to ablate the thyroid remnant undoubtedly destroys some micrometastases, the most common site of recurrence is in cervical lymph nodes, which comprises the majority of all recurrences. Future research must be directed to developing techniques to identify small cervical metastases, which in a substantial number of cases progress to overt, clinically significant metastases.

\section{Acknowledgements}

The patient organization, ThyCa: Thyroid Cancer Survivors' Association, Inc., contributed an unrestricted educational grant towards the development of the thyroid cancer guidelines. The American Thyroid Association provided the remainder of the support.

The taskforce wishes to thank Ms. Barbara Smith, Executive Director, American Thyroid Association and Ms. Sheri Slaughter, Assistant to the Taskforce, for their constant help and support. These guidelines were funded by the American Thyroid Association without support from any commercial sources.

\section{References}

1. Tunbridge WMG, Evered DC, Hall R, Appleton D, Brewis M, Clark F, Evans JG, Young E, Bird T, Smith PA 1977 The spectrum of thyroid disease in a community: The Whickham Survey. Clin Endocrinol (Oxf) 7:481-493.

2. Vander JB, Gaston EA, Dawber TR 1968 The significance of nontoxic thyroid nodules. Ann Intern Med 69:537-540.

3. Tan GH, Gharib H 1997 Thyroid incidentalomas: Management approaches to nonpalpable nodules discovered incidentally on thyroid imaging. Ann Intern Med 126: 226-231.

4. Hegedus L 2004 Clinical practice. The thyroid nodule. N Engl J Med 351:1764-1771.

5. Mandel SJ 2004 A 64-year-old woman with a thyroid nodule. JAMA 292:2632-2642.

6. Sherman SI 2003 Thyroid carcinoma. Lancet 361:501-511.

7. Jemal A, Murray T, Ward E, Samuels A, Tiwari RC, Ghafoor A, Feuer EJ, Thun MJ 2005 Cancer statistics 2005. CA Cancer J Clin 55:10-30.

8. Hodgson NC, Button J, Solorzano CC 2004 Thyroid cancer: Is the incidence still increasing? Ann Surg Oncol 11:1093-1097.

9. Singer PA, Cooper DS, Daniels GH, Ladenson PW, Greenspan FS, Levy EG, Braverman LE, Clark OH, McDougall IR, Ain KV, Dorfman SG 1996 Treatment guidelines for patients with thyroid nodules and well-differentiated thyroid cancer. American Thyroid Association. Arch Intern Med 28;156:2165-2172.

10. Thyroid Carcinoma Task Force 2001 AACE/AAES medical/surgical guidelines for clinical practice: Management of thyroid Carcinoma. American Association of Clinical Endocrinologists. Endocr Pract 7:202-220.

11. British Thyroid Association and Royal College of Physicians 2002 Guidelines for the management of thyroid cancer in adults. www.british-thyriod-association.org (Last accessed November 21, 2005).

12. Thyroid carcinoma. National Comprehensive Cancer Network. www.nccn.org/professionals/physician_gls/PDF/ thyroid.pdf (Last accessed November 21, 2005).
13. U.S. Preventive Services Task Force Ratings: Strength of Recommendations and Quality of Evidence. Guide to Clinical Preventive Services, 3rd ed., Periodic Updates, 2000-2003. Agency for Healthcare Research and Quality, Rockville, MD.

14. Marqusee E, Benson CB, Frates MC, Doubilet PM, Larsen PR, Cibas ES, Mandel SJ 2000 Usefulness of ultrasonography in the management of nodular thyroid disease. Ann Intern Med 1339:696-700.

15. Hagag P, Strauss S, Weiss M 1998 Role of ultrasoundguided fine-needle aspiration biopsy in evaluation of nonpalpable thyroid nodules. Thyroid 8:989-995.

16. Curtis RE, Rowlings PA, Deeg HJ, Shriner DA, Socié G, Travis LB, Horowitz MM, Witherspoon RP, Hoover RN, Sobocinski KA, Fraumeni JF, Boice JD, Schoch HG, Sale GE, Storb R, Travis WD, Kolb HJ, Gale RP, Passweg JR 1997 Solid cancers after bone marrow transplantation. N Engl J Med 336:897-904.

17. Pacini F, Vorontsova T, Demidchik E, Molinaro E, Agate, L, Romei C, Shavrova E, Cherstvoy ED, Ivashkevitch Y, Kuchinskaya E, Schlumberger M, Ronga G, Filesi M, Pinchera A 1997 Post-Chernobyl thyroid carcinoma in belarus children and adolescents: Comparison with naturally occurring thyroid carcinoma in Italy and France. J Clin Endocrinol Metab 81:3563-3569.

18. Hall TL, Layfield LJ, Philippe A, Rosenthal D 1989 Sources of diagnostic error in fine needle aspiration of the thyroid. Cancer 63:718-725.

19. Alexander EK, Heering JP, Benson CB, Frates MC, Doubilet PM, Cibas ES, Marqusee E 2002 Assessment of nondiagnostic ultrasound-guided fine needle aspiration of thyroid nodules. J Clin Endocrinol Metab 87:4924-4927.

20. Brander A, Viikinkoski P, Tuuhea J, Voutilainen L, Kivisaari L 1992 Clinical versus ultrasound examination of the thyroid gland in common clinical practice. J Clin Ultrasound 20:37-42.

21. Tan GH, Gharib H, Reading CC 1995 Solitary thyroid nodule. Arch Intern Med 155:2418-2423.

22. Yokozawa T, Miyauchi A, Kuma K, Sugawara M 1995 Accurate and simple method of diagnosing thyroid nodules by the modified technique of ultrasound-guided fine needle aspiration biopsy. Thyroid 5:141-145.

23. Pacini F, Pinchera A, Giani C, Grasso L, Doveri F, Baschieri L 1980 Serum thyroglobulin in thyroid carcinoma and other thyroid disorders. J Endocrinol Invest 3:283-292.

24. Elisei R, Bottici V, Luchetti F, Di Coscio G, Romei C, Grasso L, Miccoli P, Iacconi P, Basolo F, Pinchera A, Pacini F 2004 Impact of routine measurement of serum calcitonin on the diagnosis and outcome of medullary thyroid cancer: Experience in 10,864 patients with nodular thyroid disorders. J Clin Endocrinol Metab 89:163-168.

25. Hahm JR, Lee MS, Min YK, Lee MK, Kim KW, Nam SJ, Yang JH, Chung JH 2001 Routine measurement of serum calcitonin is useful for early detection of medullary thyroid carcinoma in patients with nodular thyroid diseases. Thyroid 11:73-80.

26. Niccoli P, Wion-Barbot N, Caron P, Henry JF, de Micco C, Saint Andre JP, Bigorgne JC, Modigliani E, Conte-Devolx B 1997 Interest of routine measurement of serum calcitonin: Study in a large series of thyroidectomized patients. The French Medullary Study Group. J Clin Endocrinol Metab 82:338-341.

27. Gagel RF, Hoff AO, Cote GJ 2005 Medullary thyroid carcinoma. In: Werner and Ingbar's The Thyroid: A Fundamental and Clinical Text. Lippincott Williams and Wilkins, Philadelphia, pp. 967-988. 
28. Braga M, Cavalcanti TC, Collaco LM, Graf H 2001 Efficacy of ultrasound-guided fine-needle aspiration biopsy in the diagnosis of complex thyroid nodules. J Clin Endocrinol Metab 86:4089-4091.

29. de los Santos ET, Keyhani-Rofagha S, Cunningham JJ, Mazzaferri EL 1990 Cystic thyroid nodules. The dilemma of malignant lesions. Arch Intern Med 150:1422-1427.

30. Yeh MW, Demircan O, Ituarte P, Clark OH 2004 False-negative fine-needle aspiration cytology results delay treatment and adversely affect outcome in patients with thyroid carcinoma. Thyroid 14:207-215.

31. Gharib H, Goellner JR, Johnson DA 1993 Fine-needle aspiration cytology of the thyroid. A 12-year experience with 11,000 biopsies. Clin Lab Med 13:699-709.

32. Tuttle RM, Lemar H, Burch HB 1998 Clinical features associated with an increased risk of thyroid malignancy in patients with follicular neoplasia by fine-needle aspiration. Thyroid 8:377-383.

33. Kelman AS, Rathan A, Leibowitz J, Burstein DE, Haber RS 2001 Thyroid cytology and the risk of malignancy in thyroid nodules: Importance of nuclear atypia in indeterminate specimens. Thyroid 11:271-277.

34. Segev DL, Clark DP, Zeiger MA, Umbricht C 2003 Beyond the suspicious thyroid fine needle aspirate. A review. Acta Cytol 47(5):709-722.

35. Haugen BR, Woodmansee WW, McDermott MT 2002 Towards improving the utility of fine-needle aspiration biopsy for the diagnosis of thyroid tumors. Clin Endocrinol 56:281-290.

36. Tyler DS, Winchester DJ, Caraway NP, Hickey RC, Evans DB 1994 Indeterminate fine-needle aspiration biopsy of the thyroid: Identification of subgroups at high risk for invasive carcinoma. Surgery 116:1054-1060.

37. Papini E, Guglielmi R, Bianchini A, Crescenzi A, Taccogna S, Nardi F, Panuozi C, Rinaldi R, Toscano V, Pacella CM 2002 Risk of malignancy in nonpalpable thyroid nodules: Predictive value of ultrasound and color-doppler features. J Clin Endocrinol Metab 87:1941-1946.

38. Leenhardt L, Hejblum G, Franc B, Du Pasquier F, Delbot T, Le Guillouzic D, Menegaux F, Guillausseau C, Hoang C, Turpin G, Aurengo A 1999 Indications and limits of ultrasound-guided cytology in the management of nonpalpable thyroid nodules. J Clin Endocrinol Metab 84:24-28.

39. Wienke JR, Chong WK, Fileding JR, Zou KH, Mittelstatedt CA 2003 Sonographic features of benign nodules. J Ultrasound Med 22:1027-1031.

40. Carmeci C, Jeffrey RB, McDougall IR, Nowels KW, Weigel RJ 1998 Ultrasound-guided fine-needle aspiration biopsy of thyroid masses. Thyroid 8:283-289.

41. Ylagan LR, Farkas T, Dehner LP 2004 Fine needle aspiration of the thyroid: A cytohistologic correlation and study of discrepant cases. Thyroid 14:35-41.

42. Alexander EK, Hurwitz S, Heering JP, Benson CB, Frates MC, Doubilet PM, Cibas ES, Larsen PR, Margusee E 2003 Natural history of benign solid and cystic thyroid nodules. Ann Intern Med 138:315-318.

43. Erdogan MF, Kamel N, Aras D, Akdogan A, Baskal N, Erdogan G 1998 Value of re-aspirations in benign nodular thyroid disease. Thyroid 8:1087-1090

44. Danese D, Sciacchitano S, Farsetti A, Andreoli M, Pontecorvi A 1998 Diagnostic accuracy of conventional versus sonography-guided fine-needle aspiration biopsy of thyroid nodules. Thyroid 8:15-21.

45. Orlandi A, Puscar A, Capriata E, Fideleff H 2005 Repeated fine-needle aspiration of the thyroid in benign nodular thy- roid disease: Critical evaluation of long-term follow-up. Thyroid 15:274-278.

46. Papini E, Petrucci L, Guglielmi R, Panunzi C, Rinaldo R, Bacci V, Crescenzi A, Nardi F, Fabrinni R, Pacella CM 1998 Long-term changes in nodular goiter: A 5-year prospective randomized trial of levothyroxine suppressive therapy for benign cold thyroid nodules. J Clin Endocrinol Metab 83:780-783.

47. Brander AE, Viikinkoski VP, Nickels JI, Kivisaari LM 2000 Importance of thyroid abnormalities detected at US screening: A 5-year follow-up. Radiology 215:801-806.

48. Zelmanovitz F, Genro S, Gross JL 1998 Suppressive therapy with levothyroxine for solitary thyroid nodules: A double-blind controlled clinical study and cumulative metaanalyses. J Clin Endocrinol Metab 83:3881-3885.

49. Wemeau JL, Caron P, Schvartz C, Schlienger JL, Orgiazzi J, Cousty C, Vlaeminck-Guillem V 2002 Effects of thyroidstimulating hormone suppression with levothyroxine in reducing the volume of solitary thyroid nodules and improving extranodular nonpalpable changes: A randomized, double-blind, placebo-controlled trial by the French Thyroid Research Group. J Clin Endocrinol Metab 87:4928-4934.

50. Castro MR, Caraballo PJ, Morris JC 2002 Effectiveness of thyroid hormone suppressive therapy in benign solitary thyroid nodules: A meta-analysis. J Clin Endocrinol Metab 87:4154-4159.

51. Rallison ML, Dobyns BM, Keating FR Jr, Rall JE, Tyler FH 1975 Thyroid nodularity in children. JAMA 8;233:10691072.

52. Raab SS, Silverman JF, Elsheikh TM, Thomas PA, Wakely PE 1995 Pediatric thyroid nodules: Disease demographics and clinical management as determined by fine needle aspiration biopsy. Pediatrics 95:46-49.

53. Corrias A, Einaudi S, Chiorboli E, Weber G, Crino A, Andreo M, Cesaretti G, de Sanctis L, Messina MF, Segni M, Cicchetti M, Vigone M, Pasquino AM, Spera S, de Luca F, Mussa GC, Bona G 2001 Accuracy of fine needle aspiration biopsy of thyroid nodules in detecting malignancy in childhood: Comparison with conventional clinical, laboratory, and imaging approaches. J Clin Endocrinol Metab 86:4644-4648.

54. Hung W 1999 Solitary thyroid nodules in 93 children and adolescents, a 35-years experience. Horm Res 52:15-18.

55. Gharib H, Zimmerman D, Goellner JR, Bridley SM, LeBlanc SM 1995 Fine-needle aspiration biopsy: Use in diagnosis and management of pediatric thyroid diseases. Endocr Pract 1:9-13.

56. Arda IS, Yildirim S, Demirhan B, Firat S 2001 Fine needle aspiration biopsy of thyroid nodules. Arch Dis Child 85:313-317.

57. Tan GH, Gharib H, Goellner JR, van Heerden JA, Bahn RS 1996 Management of thyroid nodules in pregnancy. Arch Intern Med 156:2317-2320.

58. Mestman JH, Goodman TM, Montoro MM 1995 Thyroid disorders of pregnancy. Endocrinol Metab Clin North Am 24:41-71.

59. Herzon FS, Morris DM, Segal MN, Rauch G, Parnell T 1994 Coexistent thyroid cancer and pregnancy. Arch Otolaryngol Head Neck Surg 120:1191-1193.

60. Moosa M, Mazzaferri EL 1997 Outcome of differentiated thyroid cancer diagnosed in pregnant women. J Clin Endocrinol Metab 82:2862-2866.

61. Mazzaferri EL, Jhiang SM 1994 Long-term impact of initial surgical and medical therapy on papillary and follicular thyroid cancer. Am J Med 97:418-428. 
62. Hay ID, Bergstralh EJ, Goellner JR, Ebersold JR, Grant CS 1993 Predicting outcome in papillary thyroid carcinoma: Development of a reliable prognostic scoring system in a cohort of 1779 patients surgically treated at one institution during 1940 through 1989. Surgery 114:1050-1057; discussion 1057-1058.

63. Shah MD, Hall FT, Eski SJ, Witterick IJ, Walfish PG, Freeman JL 2003 Clinical course of thyroid carcinoma after neck dissection. Laryngoscope 113:2102-2107

64. Wang TS, Dubner S, Sznyter LA, Heller KS 2004 Incidence of metastatic well-differentiated thyroid cancer in cervical lymph nodes. Arch Otolaryngol Head Neck Surg 130:110-113.

65. Sosa JA, Bowman HM, Tielsch JM, Powe NR, Gordon TA, Udelsman R 1998 The importance of surgeon experience for clinical and economic outcomes from thyroidectomy. Ann Surg 228:320-330.

66. Friedman M, Pacella BL Jr 1990 Total versus subtotal thyroidectomy. Arguments, approaches, and recommendations. Otolaryngol Clin North Am 23:413-427.

67. Brierley JD, Panzarella T, Tsang RW, Gospodarowicz MK, O'Sullivan B 1997 A comparison of different staging systems predictability of patient outcome. Thyroid carcinoma as an example. Cancer 79:2414-2423.

68. Hay ID, Thompson GB, Grant CS, Bergstralh EJ, Dvorak CE, Gorman CA, Mauver MS, McIver B, Mullan BP, Oberg AL, Powell CC, van Heerden JA, Goellner JA 2002 Papillary thyroid carcinoma managed at the Mayo Clinic during six decades (1940-1999): Temporal trends in initial therapy and long-term outcome in 2444 consecutively treated patients. World J Surg 26:879-885.

69. Lin JD, Chao TC, Huang MJ, Weng HF, Tzen KY 1998 Use of radioactive iodine for thyroid remnant ablation in welldifferentiated thyroid carcinoma to replace thyroid reoperation. Am J Clin Oncol 21:77-81.

70. Esnaola NF, Cantor SB, Sherman SI, Lee JE, Evans DB 2001 Optimal treatment strategy in patients with papillary thyroid cancer: A decision analysis. Surgery 130:921-930.

71. Mazzaferri EL 1999 An overview of the management of papillary and follicular thyroid carcinoma. Thyroid 9:421-427.

72. Mazzaferri EL 2000 Long-term outcome of patients with differentiated thyroid carcinoma: Effect of therapy. Endocr Pract 6:469-476.

73. Cooper DS, Specker B, Ho M, Sperling M, Ladenson PW, Ross DS, Ain KB, Bigos ST, Brierly JD, Hangen BR, Klein I, Robbins J, Sherman SI, Taylor T, Maxon HR 3rd 1998 Thyrotropin suppression and disease progression in patients with differentiated thyroid cancer: Results from the National Thyroid Cancer Treatment Cooperative Registry. Thyroid 8:737-744

74. Kim TH, Yang DS, Jung KY, Kim CY, Choi MS 2003 Value of external irradiation for locally advanced papillary thyroid cancer. Int J Radiat Oncol Biol Phys 55:1006-1012.

75. Grebe SK, Hay ID 1996 Thyroid cancer nodal metastases: Biologic significance and therapeutic considerations. Surg Oncol Clin North Am 5:43-63.

76. Scheumann GF, Gimm O, Wegener G, Hundeshagen H, Dralle H 1994 Prognostic significance and surgical management of locoregional lymph node metastases in papillary thyroid cancer. World J Surg 18:559-568.

77. Ito Y, Uruno T, Nakano K, Takamura Y, Miya A, Kobayashi K, Yokozawa T, Matsuzuka F, Kuma S, Kuma K, Miyauchi A 2003 An observation trial without surgical treatment in patients with papillary microcarcinoma of the thyroid. Thyroid 13:381-387.
78. Chow SM, Law SC, Chan JK, Au SK, Yau S, Lau WH 2003 Papillary microcarcinoma of the thyroid-Prognostic significance of lymph node metastasis and multifocality. Cancer 98:31-40.

79. Nam-Goong IS, Kim HY, Gong G, Lee HK, Hong SJ, Kim WB, Shong YK 2004 Ultrasonography-guided fine-needle aspiration of thyroid incidentaloma: Correlation with pathological findings. Clin Endocrinol (Oxf) 60:21-28.

80. Hay ID, Grant CS, van Heerden JA, Goellner JR, Ebersold JR, Bergstralh EJ 1992 Papillary thyroid microcarcinoma: A study of 535 cases observed in a 50-year period. Surgery 112:1139-1146; discussion 1146-1147.

81. Qubain SW, Nakano S, Baba M, Takao S, Aikou T 2002 Distribution of lymph node micrometastasis in pN0 well-differentiated thyroid carcinoma. Surgery 131:249-256.

82. Arturi F, Russo D, Giuffrida D, Ippolito A, Perrotti N, Vigneri R, Filetti S 1997 Early diagnosis by genetic analysis of differentiated thyroid cancer metastases in small lymph nodes. J Clin Endocrinol Metab 82:1638-1641.

83. Solorzano CC, Carneiro DM, Ramirez M, Lee TM, Irvin GL 3rd 2004 Surgeon-performed ultrasound in the management of thyroid malignancy. Am Surg 70:576-580; discussion 580-582.

84. Shimamoto K, Satake H, Sawaki A, Ishigaki T, Funahashi H, Imai T 1998 Preoperative staging of thyroid papillary carcinoma with ultrasonography. Eur J Radiol 29:4-10.

85. Stephenson BM, Wheeler MH, Clark OH 1994 The role of total thyroidectomy in the management of differentiated thyroid cancer. Curr Opin Gen Surg 53-59.

86. Kresnik E, Gallowitsch HJ, Mikosch P, Steltner H, Igere I, Gome I, Kumnig G, Lind P 2003 Fluorine-18-fluorodeoxyglucose positron emission tomography in the preoperative assessment of thyroid nodules in an endemic goiter area. Surgery 133:294-299.

87. Zbaren P, Becker M, Lang H 1997 Pretherapeutic staging of hypopharyngeal carcinoma. Clinical findings, computed tomography, and magnetic resonance imaging compared with histopathologic evaluation. Arch Otolaryngol Head Neck Surg 123:908-913.

88. Spencer CA, Bergoglio LM, Kazarosyan M, Fatemi S, LoPresti JS 2005 Clinical impact of thyroglobulin (Tg) and Tg autoantibody method differences on the management of patients with differentiated thyroid carcinomas. J Clin Endocrinol Metab 90:5566-5575.

89. Doherty GM, Skogseid BM (eds) 2001 Surgical Endocrinology. Lippincott, Williams and Wilkins, Philadelphia, PA.

90. Gharib H, Goellner JR, Zinsmeister AR, Grant CS, Van Heerden JA 1984 Fine-needle aspiration biopsy of the thyroid. The problem of suspicious cytologic findings. Ann Intern Med 101:25-28.

91. Baloch ZW, Fleisher S, LiVolsi VA, Gupta PK 2002 Diagnosis of "follicular neoplasm": A gray zone in thyroid fineneedle aspiration cytology. Diagn Cytopathol 26:41-44.

92. Sclabas GM, Staerkel GA, Shapiro SE, Fornage BD, Sherman SI, Vassillopoulou-Sellin R, Lu JE, Evans DB 2003 Fine-needle aspiration of the thyroid and correlation with histopathology in a contemporary series of 240 patients. Am J Surg 186:702-709; discussion 709-710.

93. Goldstein RE, Netterville JL, Burkey B, Johnson JE 2002 Implications of follicular neoplasms, atypia, and lesions suspicious for malignancy diagnosed by fine-needle aspiration of thyroid nodules. Ann Surg 235:656-662; discussion 662-664.

94. Schlinkert RT, van Heerden JA, Goellner JR, Gharib H, Smith SL, Rosales RF, Weaver AL 1997 Factors that predict 
malignant thyroid lesions when fine-needle aspiration is "suspicious for follicular neoplasm." Mayo Clin Proc 72:913-916.

95. Rouxel A, Hejblum G, Bernier M, Boelle PY, Menegaux F, Mansour G, Hoang C, Aurengo A, Leenhardt L 2004 Prognostic factors associated with the survival of patients developing loco-regional recurrences of differentiated thyroid carcinomas. J Clin Endocrinol Metab 89:5362-5368.

96. van Heerden JA, Hay ID, Goellner JR, Salomao D, Ebursold JR, Bergstralh EJ, Grant CS 1992 Follicular thyroid carcinoma with capsular invasion alone: A nonthreatening malignancy. Surgery 112:1130-1136; discussion 11361138.

97. Mazzaferri EL, Young RL 1981 Papillary thyroid carcinoma: A 10 year follow-up report of the impact of therapy in 576 patients. Am J Med 70:511-518.

98. DeGroot LJ, Kaplan EL, McCormick M, Straus FH 1990 Natural history, treatment, and course of papillary thyroid carcinoma. J Clin Endocrinol Metab 71:414-424.

99. Samaan NA, Schultz PN, Hickey RC, Goepfert H, Haynie TP, Johnson DA, Ordonez NG 1992 The results of various modalities of treatment of well differentiated thyroid carcinomas: A retrospective review of 1599 patients. J Clin Endocrinol Metab 75:714-720.

100. Shaha AR, Shah JP, Loree TR 1997 Differentiated thyroid cancer presenting initially with distant metastasis. Am J Surg 174:474-476.

101. Sanders LE, Cady B 1998 Differentiated thyroid cancer: Reexamination of risk groups and outcome of treatment. Arch Surg 133:419-425.

102. Kouvaraki MA, Shapiro SE, Fornage BD, Edeiken-Monro BS, Sherman Si, Vassilopoulou-Sellin R, Lee JE, Evans DB 2003 Role of preoperative ultrasonography in the surgical management of patients with thyroid cancer. Surgery 134:946-954; discussion 954-955.

103. Tisell LE, Nilsson B, Molne J, Hansson G, Fjalling M, Jansson S, Wingren U 1996 Improved survival of patients with papillary thyroid cancer after surgical microdissection. World J Surg 20:854-859.

104. Olson JA, Jr., DeBenedetti MK, Baumann DS, Wells SA Jr. 1996 Parathyroid autotransplantation during thyroidectomy. Results of long-term follow-up. Ann Surg 223:472-478; discussion 478-480.

105. Gimm O, Rath FW, Dralle H 1998 Pattern of lymph node metastases in papillary thyroid carcinoma. Br J Surg 85:252-254.

106. Henry JF, Gramatica L, Denizot A, Kvachenyuk A, Puccini M, Defechereux T 1998 Morbidity of prophylactic lymph node dissection in the central neck area in patients with papillary thyroid carcinoma. Langenbecks Arch Surg 383:167-169.

107. Cheah WK, Arici C, Ituarte PH, Siperstein AE, Duh QY, Clark $\mathrm{OH} 2002$ Complications of neck dissection for thyroid cancer. World J Surg 26:1013-1016.

108. Machens A, Hinze R, Thomusch O, Dralle H 2002 Pattern of nodal metastasis for primary and reoperative thyroid cancer.World J Surg 26:22-28.

109. Gemsenjager E, Perren A, Seifert B, Schuler G, Schweizer I, Heitz PU 2003 Lymph node surgery in papillary thyroid carcinoma. J Am Coll Surg 197:182-190.

110. Ito Y, Tomoda C, Uruno T, Takamura Y, Miya A, Kobayashi K, Matsuzuka F, Kuma K, Miyauchi A 2004 Preoperative ultrasonographic examination for lymph node metastasis: Usefulness when designing lymph node dissection for papillary microcarcinoma of the thyroid. World J Surg 28:498-501.
111. Kupferman ME, Patterson M, Mandel SJ, LiVolsi V, Weber RS 2004 Patterns of lateral neck metastasis in papillary thyroid carcinoma. Arch Otolaryngol Head Neck Surg 130:857-860.

112. Kupferman ME, Patterson DM, Mandel SJ, LiVolsi V, Weber RS 2004 Safety of modified radical neck dissection for differentiated thyroid carcinoma. Laryngoscope 114:403-406.

113. Goropoulos A, Karamoshos K, Christodoulou A, Ntitsias T, Paulou K, Samaras A, Xirou P, Efstratiou I 2004 Value of the cervical compartments in the surgical treatment of papillary thyroid carcinoma. World J Surg 28:1275-1281.

114. Pacini F, Elisei R, Capezzone M, Miccoli P, Molinaro E, Basolo F, Agate L, Bottici V, Raffaelli M, Pinchera A 2001 Contralateral papillary thyroid cancer is frequent at completion thyroidectomy with no difference in low- and high-risk patients. Thyroid 11:877-881.

115. Pasieka JL, Thompson NW, McLeod MK, Burney RE, Macha M 1992 The incidence of bilateral well-differentiated thyroid cancer found at completion thyroidectomy. World J Surg 16:711-716; discussion 716-717.

116. Kim ES, Kim TY, Koh JM, Kim YI, Hong SJ, Kim WB, Shong YK 2004 Completion thyroidectomy in patients with thyroid cancer who initially underwent unilateral operation. Clin Endocrinol (Oxf) 61:145-148.

117. Erdem E, Gulcelik MA, Kuru B, Alagol H 2003 Comparison of completion thyroidectomy and primary surgery for differentiated thyroid carcinoma. Eur J Surg Oncol 29:747-749.

118. Shaha AR, Jaffe BM 1992 Completion thyroidectomy: A critical appraisal. Surgery 112:1148-1152; discussion 1152-1153.

119. Randolph GW, Daniels GH 2002 Radioactive iodine lobe ablation as an alternative to completion thyroidectomy for follicular carcinoma of the thyroid. Thyroid 12:989-996.

120. Loh KC, Greenspan FS, Gee L, Miller TR, Yeo PP 1997 Pathological tumor-node-metastasis (pTNM) staging for papillary and follicular thyroid carcinomas: A retrospective analysis of 700 patients. J Clin Endocrinol Metab 82:3553-3562.

121. Wittekind C, Compton CC, Greene FL, Sobin LH 2002 TNM residual tumor classification revisited. Cancer 94:2511-2516.

122. Byar DP, Green SB, Dor P, Williams ED, Colon J, van Gilse HA, Mayer M, Sylvester RJ, van Glabbeke M 1979 A prognostic index for thyroid carcinoma. A study of the E.O.R.T.C. Thyroid Cancer Cooperative Group. Eur J Cancer 15:1033-1041.

123. Cady B, Rossi R 1998 An expanded view of risk-group definition in differentiated thyroid carcinoma. Surgery 104:947-953.

124. Shaha AR, Loree TR, Shah JP 1995 Prognostic factors and risk group analysis in follicular carcinoma of the thyroid. Surgery 118:1131-1136; discussion 1136-1138.

125. Sherman SI, Brierley JD, Sperling M, Ain KB, Bigos SJ, Cooper DS, Hangen BR, Ho M, Klein I, Ladenson PW, Robbins J, Ross DS, Specker B, Taylor T, Maxon HR 3rd 1998 Prospective multicenter study of thyroid carcinoma treatment: Initial analysis of staging and outcome. National Thyroid Cancer Treatment Cooperative Study Registry Group. Cancer 83:1012-1021.

126. Mazzaferri EL, Jhiang SM 1994 Differentiated thyroid cancer long-term impact of initial therapy. Trans Am Clin Climatol Assoc 106:151-168; discussion 168-170.

127. Taylor T, Specker B, Robbins J, Sperling M, Ho M, Ain K, Bigos ST, Brierly J, Cooper D, Haugen B, Hay I, Hertzberg V, Klein I, Klein H, Ladenson P, Nishiyama R, Ross D, 
Sherman S, Maxon HR 1998 Outcome after treatment of high-risk papillary and non-Hurthle-cell follicular thyroid carcinoma. Ann Intern Med 129:622-627.

128. Sawka AM, Thephamongkhol K, Brouwers M, Thabane L, Browman G, Gerstein HC 2004 Clinical review 170: A systematic review and metaanalysis of the effectiveness of radioactive iodine remnant ablation for well-differentiated thyroid cancer. J Clin Endocrinol Metab 89:3668-3676.

129. Kim S, Wei JP, Braveman JM, Brams DM 2004 Predicting outcome and directing therapy for papillary thyroid carcinoma. Arch Surg 139:390-394; discussion 393-394.

130. Sugitani I, Fujimoto Y 1999 Symptomatic versus asymptomatic papillary thyroid microcarcinoma: A retrospective analysis of surgical outcome and prognostic factors. Endocr J 46:209-216.

131. Hundahl SA, Fleming ID, Fremgen AM, Menck HR 1998 A National Cancer Data Base report on 53,856 cases of thyroid carcinoma treated in the U.S., 1985-1995. Cancer 83:2638-2648.

132. Mazzaferri EL 1997 Thyroid remnant ${ }^{131}$ I ablation for papillary and follicular thyroid carcinoma. Thyroid 7:265-271.

133. Edmonds CJ, Hayes S, Kermode JC, Thompson BD 1977 Measurement of serum TSH and thyroid hormones in the management of treatment of thyroid carcinoma with radioiodine. Br J Radiol 50:799-807.

134. Torres MS, Ramirez L, Simkin PH, Braverman LE, Emerson $\mathrm{CH} 2001$ Effect of various doses of recombinant human thyrotropin on the thyroid radioactive iodine uptake and serum levels of thyroid hormones and thyroglobulin in normal subjects. J Clin Endocrinol Metab 86:1660-1664.

135. Hershman JM, Edwards CL 1972 Serum thyrotropin (TSH) levels after thyroid ablation compared with TSH levels after exogenous bovine TSH: Implications for 131-I treatment of thyroid carcinoma. J Clin Endocrinol Metab 34:814-818.

136. Martin ND 1978 Endogenous serum TSH levels and metastatic survey scans in thyroid cancer patients using triiodothyronine withdrawal. Clin Nucl Med 3:401-403.

137. Hilts SV, Hellman D, Anderson J, Woolfenden J, Van Antwerp J, Patton D 1979 Serial TSH determination after T3 withdrawal or thyroidectomy in the therapy of thyroid carcinoma. J Nucl Med 20:928-932.

138. Goldman JM, Line BR, Aamodt RL, Robobins J 1980 Influence of triiodothyronine withdrawal time on 131I uptake postthyroidectomy for thyroid cancer. J Clin Endocrinol Metab 50:734-739.

139. Schneider AB, Line B, Goldman JM, Robbins J 1981 Sequential serum thyroglobulin determinations, ${ }^{131}$ I scans, and ${ }^{131} \mathrm{I}$ uptakes after triiodothyronine withdrawal in patients with thyroid cancer. J Clin Endocrinol Metab 53:1199-1206.

140. Maxon HR, Thomas SR, Hertzberg VS, Kereiakes JG, Chen IW, Sperling MI, Saenger EL 1983 Relation between effective radiation dose and outcome of radioiodine therapy for thyroid cancer. N Engl J Med 309:937-941.

141. Liel Y 2002 Preparation for radioactive iodine administration in differentiated thyroid cancer patients. Clin Endocrinol (Oxf) 57:523-527.

142. Sanchez R, Espinosa-de-los-Monteros AL, Mendoza V, Brea E, Hernandez I, Sosa E, Mercado M 2002 Adequate thyroid-stimulating hormone levels after levothyroxine discontinuation in the follow-up of patients with well-differentiated thyroid carcinoma. Arch Med Res 33:478-481.

143. Grigsby PW, Siegel BA, Bekker S, Clutter WE, Moley JF 2004 Preparation of patients with thyroid cancer for ${ }^{131} \mathrm{I}$ scintigraphy or therapy by 1-3 weeks of thyroxine discontinuation. J Nucl Med 45:567-570.
144. Serhal DI, Nasrallah MP, Arafah BM 2004 Rapid rise in serum thyrotropin concentrations after thyroidectomy or withdrawal of suppressive thyroxine therapy in preparation for radioactive iodine administration to patients with differentiated thyroid cancer. J Clin Endocrinol Metab 89:3285-3289.

145. Guimaraes V, DeGroot LJ 1996 Moderate hypothyroidism in preparation for whole body 131I scintiscans and thyroglobulin testing. Thyroid 6:69-73.

146. Maxon HR 1999 Detection of residual and recurrent thyroid cancer by radionuclide imaging. Thyroid 9:443-446.

147. Carril JM, Quirce R, Serrano J, Banzo I, Jimenez-Bonilla JF, Tabuenca O, Barquin RG 1997 Total-body scintigraphy with thallium-201 and iodine-131 in the follow-up of differentiated thyroid cancer J Nucl Med 38:686-692.

148. Muratet JP, Giraud P, Daver A, Minier JF, Gamelin E, Larra F 1997 Predicting the efficacy of first iodine-131 treatment in differentiated thyroid carcinoma. J Nucl Med 38:1362-1368.

149. Park HM, Park YH, Zhou XH 1997 Detection of thyroid remnant/metastasis without stunning: An ongoing dilemma. Thyroid 7:277-280.

150. Hilditch TE, Dempsey MF, Bolster AA, McMenemin RM, Reed NS 2002 Self-stunning in thyroid ablation: Evidence from comparative studies of diagnostic ${ }^{131}$ I and ${ }^{123}$ I. Eur J Nucl Med Mol Imaging 29:783-788.

151. Lassmann M, Luster M, Hanscheid H, Reiners C 2004 Impact of (131)I diagnostic activities on the biokinetics of thyroid remnants. J Nucl Med 45:619-625.

152. Anderson GS, Fish S, Nakhoda K, Zhuang H, Alava A, Mandel SJ 2003 Comparsion of I-123 and I-131 for wholebody imaging after stimulation by recombinant human thyrotropin: A preliminary report. Clin Nucl Med 28:93-96.

153. Gerard SK, Cavalieri RR 2002 I-123 diagnostic thyroid tumor whole-body scanning with imaging at 6,24 , and 48 hours. Clin Nucl Med 27:1-8.

154. Rosario PW, Reis JS, Barroso AL, Rezende LL, Padrao EL, Fagundes TA 2004 Efficacy of low and high ${ }^{131}$ I doses for thyroid remnant ablation in patients with differentiated thyroid carcinoma based on post-operative cervical uptake. Nucl Med Commun 25:1077-1081.

155. Bal C, Padhy AK, Jana S, Pant GS, Basu AK 1996 Prospective randomized clinical trial to evaluate the optimal dose of $131 \mathrm{I}$ for remnant ablation in patients with differentiated thyroid carcinoma. Cancer 77:2574-2580.

156. Creutzig H 1987 High or low dose radioiodine ablation of thyroid remnants? Eur J Nucl Med 12:500-502.

157. Johansen K, Woodhouse NJ, Odugbesan O 1991 Comparison of $1073 \mathrm{MBq}$ and $3700 \mathrm{MBq}$ iodine-131 in postoperative ablation of residual thyroid tissue in patients with differentiated thyroid cancer. J Nucl Med 32:252-254.

158. Doi SA, Woodhouse NJ 2000 Ablation of the thyroid remnant and ${ }^{131} \mathrm{I}$ dose in differentiated thyroid cancer. Clin Endocrinol (Oxf) 52:765-773.

159. Robbins RJ, Larson SM, Sinha N, Shaha A, Divgi C, Pentlow KS, Gihossein R, Tuttle RM 2002 A retrospective review of the effectiveness of recombinant human TSH as a preparation for radioiodine thyroid remnant ablation. J Nucl Med 43:1482-1488.

160. Pacini F, Molinaro E, Castagna MG, Lippi F, Ceccarelli C, Agate L, Elisei R, Pinchera A 2002 Ablation of thyroid residues with $30 \mathrm{mCi}(131) \mathrm{I}$ : A comparison in thyroid cancer patients prepared with recombinant human TSH or thyroid hormone withdrawal. J Clin Endocrinol Metab 87:4063-4068. 
161. Barbaro D, Boni G, Meucci G, Simi U, Lapi P, Orsini P, Pasquini G, Piazza F, Caciagli M, Mariani G, 2003 Radioiodine treatment with $30 \mathrm{mCi}$ after recombinant human thyrotropin stimulation in thyroid cancer: Effectiveness for postsurgical remnants ablation and possible role of iodine content in L-thyroxine in the outcome of ablation. J Clin Endocrinol Metab 88:4110-4115.

162. Maxon HR, Thomas SR, Boehringer A, Drilling J, Sperling MI, Sparks JC, Chen IW 1983 Low iodine diet in I-131 ablation of thyroid remnants. Clin Nucl Med 8:123-126.

163. Goslings BM 1975 Proceedings: Effect of a low iodine diet on 131-I therapy in follicular thyroid carcinomata. J Endocrinol 64:30P.

164. Pluijmen MJ, Eustatia-Rutten C, Goslings BM, Stokkel MP, Arias AM, Diamant M, Romijn JA, Smit JW 2003 Effects of low-iodide diet on postsurgical radioiodide ablation therapy in patients with differentiated thyroid carcinoma. Clin Endocrinol (Oxf) 58:428-435.

165. Fatourechi V, Hay ID, Mullan BP, Wiseman GA, EghbaliFatourechi GZ, Thorson LM, Gorman CA 2000 Are posttherapy radioiodine scans informative and do they influence subsequent therapy of patients with differentiated thyroid cancer? Thyroid 10:573-577.

166. Sherman SI, Tielens ET, Sostre S, Wharam MD Jr, Ladenson PW 1994 Clinical utility of posttreatment radioiodine scans in the management of patients with thyroid carcinoma. J Clin Endocrinol Metab 78:629-634.

167. Souza Rosario PW, Barroso AL, Rezende LL, Padrao EL, Fagundes TA, Penna GC, Purisch S 2004 Post I-131 therapy scanning in patients with thyroid carcinoma metastases: An unnecessary cost or a relevant contribution? Clin Nucl Med 29:795-798.

168. McGriff NJ, Csako G, Gourgiotis L, Lori CG, Pucino F, Sarlis NJ 2002 Effects of thyroid hormone suppression therapy on adverse clinical outcomes in thyroid cancer. Ann Med 34:554-564.

169. Pujol P, Daures JP, Nsakala N, Baldet L, Bringer J, Jaffiol C 1996 Degree of thyrotropin suppression as a prognostic determinant in differentiated thyroid cancer. J Clin Endocrinol Metab 81:4318-4323.

170. Toft AD 2001 Clinical practice. Subclinical hyperthyroidism. N Engl J Med 345:512-516.

171. Wilson PC, Millar BM, Brierley JD 2004 The management of advanced thyroid cancer. Clin Oncol (R Coll Radiol) 16:561-568

172. Ford D, Giridharan S, McConkey C, Hartley A, Brammer C, Watkinson JC, Glaholm J 2003 External beam radiotherapy in the management of differentiated thyroid cancer. Clin Oncol (R Coll Radiol) 15:337-341.

173. Mazzarotto R, Cesaro MG, Lora O, Rubello D, Casara D, Sotti G 2000 The role of external beam radiotherapy in the management of differentiated thyroid cancer. Biomed Pharmacother 54:345-349.

174. Tsang RW, Brierley JD, Simpson WJ, Panzarella T, Gospodarowicz MK, Sutcliffe SB 1998 The effects of surgery, radioiodine, and external radiation therapy on the clinical outcome of patients with differentiated thyroid carcinoma. Cancer 82:375-388.

175. Kim JH, Leeper RD 1983 Combination adriamycin and radiation therapy for locally advanced carcinoma of the thyroid gland. Int J Radiat Oncol Biol Phys 9:565-567.

176. Kim JH, Leeper RD 1987 Treatment of locally advanced thyroid carcinoma with combination doxorubicin and radiation therapy. Cancer 60:2372-2375.
177. Schlumberger M, Berg G, Cohen O, Duntas L, Jamar F, Jarzab B, Limbert E, Lind P, Pacini F, Reiners C, Sanchez Franco F, Toft A, Wiersinga WM 2004 Follow-up of lowrisk patients with differentiated thyroid carcinoma: A European perspective. Eur J Endocrinol 150:105-112.

178. Toubeau M, Touzery C, Arveux P, Chaplain G, Vaillant G, Berriolo A, Riedinger JM, Boichot C, Cochet A, Brunolte F 2004 Predictive value for disease progression of serum thyroglobulin levels measured in the postoperative period and after (131)I ablation therapy in patients with differentiated thyroid cancer. J Nucl Med 45:988-994.

179. Rouxel A, Hejblum G, Bernier MO, Boelle PY, Menegaux F, Mansour G, Hoang C, Aurengo A, Leenhardt L 2004 Prognostic factors associated with the survival of patients developing loco-regional recurrences of differentiated thyroid carcinomas. J Clin Endocrinol Metab 89:53625368 .

180. Wenig BM, Thompson LD, Adair CF, Shmookler B, Heffess CS 1998 Thyroid papillary carcinoma of columnar cell type: A clinicopathologic study of 16 cases. Cancer 82:740-753.

181. Prendiville S, Burman KD, Ringel MD, Shmookler BM, Deeb ZE, Wolfe K, Azumi N, Wartofsky L, Sessions RB 2000 Tall cell variant: An aggressive form of papillary thyroid carcinoma. Otolaryngol Head Neck Surg 122:352-357.

182. Akslen LA, Livolsi VA 2000 Prognostic significance of histologic grading compared with subclassification of papillary thyroid carcinoma. Cancer 88:1902-1908.

183. Cailleux AF, Baudin E, Travagli JP, Ricard M, Schlumberger M 2000 Is diagnostic iodine-131 scanning useful after total thyroid ablation for differentiated thyroid cancer? J Clin Endocrinol Metab 85:175-178.

184. Bachelot A, Cailleux AF, Klain M, Baudin E, Ricard M, Bellon N, Caillou B, Travagli JP, Schlumberger M 2002 Relationship between tumor burden and serum thyroglobulin level in patients with papillary and follicular thyroid carcinoma. Thyroid 12:707-711.

185. Eustatia-Rutten CF, Smit JW, Romijn JA, van der KleijCorssmit EP, Pereira AM, Stokkel MP, Kievit J 2004 Diagnostic value of serum thyroglobulin measurements in the follow-up of differentiated thyroid carcinoma, a structured meta-analysis. Clin Endocrinol (Oxf) 61:61-74.

186. Mazzaferri EL, Robbins RJ, Braverman LE, Pacini F, Haugen B, Wartofsky L, Haugen BR, Sherman SI, Cooper DS, Braunstein GD, Lee S, Davies TE, Arafan BM, Ladenson PW, Pinchira A 2003 Authors' response: A consensus report of the role of serum thyroglobulin as a monitoring method for low-risk patients with papillary thyroid carcinoma. J Clin Endocrinol Metab 88:4508-4509.

187. Bachelot A, Leboulleux S, Baudin E, Hartl DM, Caillou B, Travagli JP, Schlumberger M 2005 Neck recurrence from thyroid carcinoma: Serum thyroglobulin and high-dose total body scan are not reliable criteria for cure after radioiodine treatment. Clin Endocrinol (Oxf) 62:376-379.

188. Robbins RJ, Srivastava S, Shaha A, Ghossein R, Larson SM, Fleisher M, Tuttle RM 2004 Factors influencing the basal and recombinant human thyrotropin-stimulated serum thyroglobulin in patients with metastatic thyroid carcinoma. J Clin Endocrinol Metab 89:6010-6016.

189. Haugen BR, Pacini F, Reiners C, Schlumberger M, Ladenson PW, Sherman SI, Cooper DS, Graham KE, Braverman LE, Skarulis MC, Davies TF, De Groot LJ, Mazzaferri EL, Daniels GH, Ross DS, Luster M, Samuels MH, Becker DV, Maxon HR, Cavalieri RR, Spencer CA, McEllin K, Weintraub BD, Ridgway EC 1999 A comparison of recombinant human thyrotropin and thyroid hormone withdrawal for 
the detection of thyroid remnant or cancer. J Clin Endocrinol Metab 84:3877-3885.

190. David A, Blotta A, Bondanelli M, Rossi R, Roti E, Braverman LE, Busulti L, degli Uberti EC 2001 Serum thyroglobulin concentrations and (131)I whole-body scan results in patients with differentiated thyroid carcinoma after administration of recombinant human thyroid-stimulating hormone. J Nucl Med 42:1470-1475.

191. Mazzaferri EL, Kloos RT 2002 Is diagnostic iodine-131 scanning with recombinant human TSH (rhTSH) useful in the follow-up of differentiated thyroid cancer after thyroid ablation? J Clin Endocrinol Metab 87:1490-1498.

192. Haugen BR, Ridgway EC, McLaughlin BA, McDermott MT 2002 Clinical comparison of whole-body radioiodine scan and serum thyroglobulin after stimulation with recombinant human thyrotropin. Thyroid 12:37-43.

193. Lima N, Cavaliere H, Tomimori E, Knobel M, MedeirosNeto G 2002 Prognostic value of serial serum thyroglobulin determinations after total thyroidectomy for differentiated thyroid cancer. J Endocrinol Invest 25:110-115.

194. Wartofsky L 2002 Management of low-risk well-differentiated thyroid cancer based only on thyroglobulin measurement after recombinant human thyrotropin. Thyroid 12:583-590.

195. Spencer CA, LoPresti JS, Fatemi S, Nicoloff JT 1999 Detection of residual and recurrent differentiated thyroid carcinoma by serum thyroglobulin measurement. Thyroid 9:435-441.

196. Hollowell JG, Staehling NW, Flanders WD, Hannon WH, Gunter EW, Spencer CA, Braverman LE 2002 Serum TSH, $\mathrm{T}(4)$, and thyroid antibodies in the United States population (1988 to 1994): National Health and Nutrition Examination Survey (NHANES III). J Clin Endocrinol Metab 87:489-499.

197. Spencer CA 2004 Challenges of serum thyroglobulin (thyroglobulin) measurement in the presence of thyroglobulin autoantibodies. J Clin Endocrinol Metab 89:3702-3704.

198. Spencer CA, Takeuchi M, Kazarosyan M, Wang CC, Guttler RB, Singer PA, Fatemi S, Lo Presti JS, Nicoloff JT 1998 Serum thyroglobulin autoantibodies: Prevalence, influence on serum thyroglobulin measurement, and prognostic significance in patients with differentiated thyroid carcinoma. J Clin Endocrinol Metab 83:1121-1127.

199. Chiovato L, Latrofa F, Braverman LE, Pacini F, Capezzone M, Masserini L, Grasso L, Pinchera A 2003 Disappearance of humoral thyroid autoimmunity after complete removal of thyroid antigens. Ann Intern Med 2003; 139:346-351.

200. David A, Blotta A, Rossi R, Zatelli MC, Bondanelli M, Roti E, Braverman LE, Busutti L, degli Uberti EC 2005 Clinical value of different responses of serum thyroglobulin to recombinant human thyrotropin in the follow-up of patients with differentiated thyroid carcinoma. Thyroid 15:267-273.

201. Baudin E, Do Cao C, Cailleux AF, Leboulleux S, Travagli JP, Schlumberger M 2003 Positive predictive value of serum thyroglobulin levels, measured during the first year of follow-up after thyroid hormone withdrawal, in thyroid cancer patients. J Clin Endocrinol Metab 88:1107-1111.

202. Schaap J, Eustatia-Rutten CF, Stokkel M, Links TP, Diamant M, van der Velde EA, Romijn JA, Smit JW 2002 Does radioiodine therapy have disadvantageous effects in non-iodine accumulating differentiated thyroid carcinoma? Clin Endocrinol 57:117-124.

203. Schlumberger M, Mancusi F, Baudin E, Pacini F 1997 131I Therapy for elevated thyroglobulin levels. Thyroid 7:273-276.
204. Mazzaferri EL, Kloos RT 2001 Current approaches to primary therapy for papillary and follicular thyroid cancer. J Clin Endocrinol Metab 86:1447-1463.

205. Pacini F, Capezzone M, Elisei R, Ceccarelli C, Taddei D, Pinchera A 2002 Diagnostic 131-iodine whole-body scan may be avoided in thyroid cancer patients who have undetectable stimulated serum thyroglobulin levels after initial treatment. J Clin Endocrinol Metab 87:1499-1501.

206. Koh JM, Kim ES, Ryu JS, Hong SJ, Kim WB, Shong YK 2003 Effects of therapeutic doses of 131I in thyroid papillary carcinoma patients with elevated thyroglobulin level and negative ${ }^{131}$ I whole-body scan: Comparative study. Clin Endocrinol (Oxf) 58:421-427.

207. Torlontano M, Crocetti U, D'Aloiso L, Bonfitto N, Di Giorgio A, Modoni S, Valle G, Frusciante V, Bisceglia M, Filelti S, Schlumberger M, Trischilta V 2003 Serum thyroglobulin and 131I whole body scan after recombinant human TSH stimulation in the follow-up of low-risk patients with differentiated thyroid cancer. Eur J Endocrinol 148:19-24.

208. Pacini F, Molinaro E, Castagna MG, Agate L, Elisei R, Ceccarelli C, Lippi F, Taddei D, Grasso L, Pinchera A 2003 Recombinant human thyrotropin-stimulated serum thyroglobulin combined with neck ultrasonography has the highest sensitivity in monitoring differentiated thyroid carcinoma. J Clin Endocrinol Metab 88:3668-3673.

209. Wang PW, Wang ST, Liu RT, Chien WY, Tung SC, Lu YC, Chen HY, Lee CH 1999 Levothyroxine suppression of thyroglobulin in patients with differentiated thyroid carcinoma. J Clin Endocrinol Metab 84:4549-4553.

210. Leeper RD 1973 The effect of 131 I therapy on survival of patients with metastatic papillary or follicular thyroid carcinoma. J Clin Endocrinol Metab 36:1143-1152.

211. Beierwaltes WH, Nishiyama RH, Thompson NW, Copp JE, Kubo A 1982 Survival time and "cure" in papillary and follicular thyroid carcinoma with distant metastases: Statistics following University of Michigan therapy. J Nucl Med 23:561-568.

212. Bernier MO, Leenhardt L, Hoang C, Aurengo A, Mary JY, Menegaux F, Enkaoua E, Turpin G, Chiras J, Saillant G, Hejblum G 2001 Survival and therapeutic modalities in patients with bone metastases of differentiated thyroid carcinomas. J Clin Endocrinol Metab 86:1568-1573.

213. Dupuy DE, Monchik JM, Decrea C, Pisharodi L 2001 Radiofrequency ablation of regional recurrence from well-differentiated thyroid malignancy. Surgery 130:971-977.

214. Lewis BD, Hay ID, Charboneau JW, McIver B, Reading CC, Goellner JR 2002 Percutaneous ethanol injection for treatment of cervical lymph node metastases in patients with papillary thyroid carcinoma. Am J Roentgenol 178:699-704.

215. Eustatia-Rutten CF, Romijn JA, Guijt MJ, Vielvoye GJ, van den Berg R, Corssmit EP, Pereira AM, Smit JW 2003 Outcome of palliative embolization of bone metastases in differentiated thyroid carcinoma. J Clin Endocrinol Metab 88:3184-3189.

216. Kloos RT, Mazzaferri EL 2005 A single recombinant hu-man thyrotrophin-stimulated serum thyroglobulin measurement predicts differentiated thyroid carcinoma metastases three to five years later. J Clin Endocrinol Metab 90:5047-5057.

217. Uchino S, Noguchi S, Yamashita H, Watanabe S 2004 Modified radical neck dissection for differentiated thyroid cancer: Operative technique. World J Surg 28:1199-1203.

218. Noguchi S, Yamashita H, Murakami N, Nakayama I, Toda M, Kawamoto H 1996 Small carcinomas of the thyroid. A long-term follow-up of 867 patients. Arch Surg 131:187-191. 
219. Marchesi M, Biffoni M, Biancari F, Berni A, Campana FP 2003 Predictors of outcome for patients with differentiated and aggressive thyroid carcinoma. Eur J Surg Suppl 588:46-50.

220. Ge JH, Zhao RL, Hu JL, Zhou WA 2004 Surgical treatment of advanced thyroid carcinoma with aero-digestive invasion. Zhonghua Er Bi Yan Hou Ke Za Zhi 39:237-240.

221. Avenia N, Ragusa M, Monacelli M, Calzolari F, Daddi N, Di Carlo L, Semeraro A, Puma F 2004 Locally advanced thyroid cancer: Therapeutic options. Chir Ital 56:501-508.

222. McCaffrey JC 2000 Evaluation and treatment of aerodigestive tract invasion by well-differentiated thyroid carcinoma. Cancer Control 7:246-252.

223. Musholt TJ, Musholt PB, Behrend M, Raab R, Scheumann GF, Klempnauer J 1999 Invasive differentiated thyroid carcinoma: Tracheal resection and reconstruction procedures in the hands of the endocrine surgeon. Surgery 126: 1078-1087; discussion 1087-1088.

224. Czaja JM, McCaffrey TV 1997 The surgical management of laryngotracheal invasion by well-differentiated papillary carcinoma. Arch Otolaryngol Head Neck Surg 123:484-490.

225. Van Nostrand D, Atkins F, Yeganeh F, Acio E, Bursaw R, Wartofsky L 2002 Dosimetrically determined doses of radioiodine for the treatment of metastatic thyroid carcinoma. Thyroid 12:121-134.

226. Brierley JD, Tsang RW 1999 External-beam radiation therapy in the treatment of differentiated thyroid cancer. Semin Surg Oncol 16:42-49.

227. Robbins RJ, Schlumberger MJ 2005 The evolving role of (131)I for the treatment of differentiated thyroid carcinoma. J Nucl Med 46:28S-37S.

228. Samuel AM, Rajashekharrao B, Shah DH 1998 Pulmonary metastases in children and adolescents with well-differentiated thyroid cancer. J Nucl Med 39:1531-1536.

229. Rudavsky AZ, Freeman LM 1997 Treatment of scan-negative, thyroglobulin-positive metastatic thyroid cancer using radioiodine 131I and recombinant human thyroid stimulating hormone. J Clin Endocrinol Metab 82:11-14.

230. Ringel MD, Ladenson PW 1996 Diagnostic accuracy of 131I scanning with recombinant human thyrotropin versus thyroid hormone withdrawal in a patient with metastatic thyroid carcinoma and hypopituitarism. J Clin Endocrinol Metab 81:1724-1725.

231. Luster M, Lassmann M, Haenscheid H, Michalowski U, Incerti C, Reiners C 2000 Use of recombinant human thyrotropin before radioiodine therapy in patients with advanced differentiated thyroid carcinoma. J Clin Endocrinol Metab 85:3640-3645.

232. Mariani G, Ferdeghini M, Augeri C, Villa G, Taddei GZ, Scopinaro G, Boni G, Bodei L, Rabitti C, Molinari E, Bianchi R 2000 Clinical experience with recombinant human thyrotrophin (rhTSH) in the management of patients with differentiated thyroid cancer. Cancer Biother Radiopharm 15:211-217.

233. Perros P 1999 Recombinant human thyroid-stimulating hormone (rhTSH) in the radioablation of well-differentiated thyroid cancer: Preliminary therapeutic experience. J Endocrinol Invest 22:30-34.

234. Lippi F, Capezzone M, Angelini F, Taddei D, Molinaro E, Pinchera A, Pacini F 2001 Radioiodine treatment of metastatic differentiated thyroid cancer in patients on L-thyroxine, using recombinant human TSH. Eur J Endocrinol 144:5-11.

235. Pellegriti G, Scollo C, Giuffrida D, Vigneri R, Squatrito S, Pezzino V 2001 Usefulness of recombinant human thy- rotropin in the radiometabolic treatment of selected patients with thyroid cancer. Thyroid 11:1025-1030.

236. Adler ML, Macapinlac HA, Robbins RJ 1998 Radioiodine treatment of thyroid cancer with the aid of recombinant human thyrotropin. Endocr Pract 4:282-286.

237. Chiu AC, Delpassand ES, Sherman SI 1997 Prognosis and treatment of brain metastases in thyroid carcinoma. J Clin Endocrinol Metab 82:3637-3642.

238. Vargas GE, Uy H, Bazan C, Guise TA, Bruder JM 1999 Hemiplegia after thyrotropin alfa in a hypothyroid patient with thyroid carcinoma metastatic to the brain. J Clin Endocrinol Metab 84:3867-3871.

239. Robbins RJ, Voelker E, Wang W, Macapinlac HA, Larson SM 2000 Compassionate use of recombinant human thyrotropin to facilitate radioiodine therapy: Case report and review of literature. Endocr Pract 6:460-464.

240. Braga M, Ringel MD, Cooper DS 2001 Sudden enlargement of local recurrent thyroid tumor after recombinant human TSH administration. J Clin Endocrinol Metab 86:5148-5151.

241. Pons F, Carrio I, Estorch M, Ginjaume M, Pons J, Milian R 1987 Lithium as an adjuvant of iodine-131 uptake when treating patients with well-differentiated thyroid carcinoma. Clin Nucl Med 12:644-647.

242. Koong SS, Reynolds JC, Movius EG, Keenan AM, Ain KB, Lakshmanan MC, Robbins J 1999 Lithium as a potential adjuvant to ${ }^{131}$ I therapy of metastatic, well differentiated thyroid carcinoma. J Clin Endocrinol Metab 84:912-916.

243. Ronga G, Filesi M, Montesano T, Di Nicola AD, Pace C, Travascio L, Ventroni G, Antonaci A, Vestri AR 2004 Lung metastases from differentiated thyroid carcinoma. A 40 years' experience. Q J Nucl Med Mol Imaging 48:12-19.

244. Lin JD, Chao TC, Chou SC, Hsueh C 2004 Papillary thyroid carcinomas with lung metastases. Thyroid 14:1091-1096.

245. Shoup M, Stojadinovic A, Nissan A, Ghossein RA, Freedman S, Brennan MF, Shah JP, Shaha AR 2003 Prognostic indicators of outcomes in patients with distant metastases from differentiated thyroid carcinoma. J Am Coll Surg 197:191-197.

246. Zettinig G, Fueger BJ, Passler C, Kaserer K, Pirich C, Dudczak R, Niederle B 2002 Long-term follow-up of patients with bone metastases from differentiated thyroid carcinoma-Surgery or conventional therapy? Clin Endocrinol (Oxf) 56:377-382.

247. Pittas AG, Adler M, Fazzari M, Tickoo S, Rosai J, Larson SM, Robbins RJ 2000 Bone metastases from thyroid carcinoma: Clinical characteristics and prognostic variables in one hundred forty-six patients. Thyroid 10:261-268.

248. Schlumberger M, Challeton C, De Vathaire F, Travagli J-P, Gardet P, Lumbroso J-D, Francese C, Fontaine F, Ricard M, Parmentier C 1996 Radioactive iodine treatment and external radiotherapy for lung and bone metastases from thyroid carcinoma. J Nucl Med 37:598-605.

249. Dinneen SF, Valimaki MJ, Bergstralh EJ, Goellner JR, Gorman CA, Hay ID 1995 Distant metastases in papillary thyroid carcinoma: 100 cases observed at one institution during 5 decades. J Clin Endocrinol Metab 80:2041-2045.

250. Foote RL, Brown PD, Garces YI, McIver B, Kasperbauer JL 2003 Is there a role for radiation therapy in the management of Hurthle cell carcinoma? Int J Radiat Oncol Biol Phys 56:1067-1072.

251. Pak H, Gourgiotis L, Chang WI, Guthrie LC, Skarulis MC, Reynolds JC, Merino MJ, Schrump DS, Libutti SK, Alexander HR Jr, Sarlis NJ 2003 Role of metastasectomy in the management of thyroid carcinoma: The NIH experience. J Surg Oncol 82:10-18. 
252. Vitale G, Fonderico F, Martignetti A, Caraglia M, Ciccarelli A, Nuzzo V, Abbruzzese A, Lupoli G 2001 Pamidronate improves the quality of life and induces clinical remission of bone metastases in patients with thyroid cancer. Br J Cancer 84:1586-1590.

253. Kitamura Y, Shimizu K, Nagahama M, Sugino K, Ozaki O, Mimura T, Ito K, Tanaka S 1999 Immediate causes of death in thyroid carcinoma: Clinicopathological analysis of 161 fatal cases. J Clin Endocrinol Metab 84:4043-4049.

254. Benua RS, Cicale NR, Sonenberg M, Rawson RW 1962 The relation of radioiodine dosimetry to results and complications in the treatment of metastatic thyroid cancer. AJR 87:171.

255. Ilgan S, Karacalioglu AO, Pabuscu Y, Atac GK, Arslan N, Ozturk E, Gunalp B, Ozguven MA 2004 Iodine-131 treatment and high-resolution CT: Results in patients with lung metastases from differentiated thyroid carcinoma. Eur J Nucl Med Mol Imaging 3:825-830.

256. Fatourechi V, Hay ID, Javedan H, Wiseman GA, Mullan BP, Gorman CA 2002 Lack of impact of radioiodine therapy in thyroglobulin-positive, diagnostic whole-body scannegative patients with follicular cell-derived thyroid cancer. J Clin Endocrinol Metab 87:1521-1526.

257. Wang W, Larson SM, Fazzari M, Tickoo SK, Kolbert K, Sgouros G, Yeung H, Macapinlac H, Rosai J, Robbins RJ 2000 Prognostic value of [18F]fluorodeoxyglucose positron emission tomographic scanning in patients with thyroid cancer. J Clin Endocrinol Metab 85:1107-1113.

258. Wang W, Larson SM, Tuttle RM, Kalaigian H, Kolbert K, Sonenberg M, Robbins RJ 2001 Resistance of [18f]-fluorodeoxyglucose-avid metastatic thyroid cancer lesions to treatment with high-dose radioactive iodine. Thyroid 11:1169-1175.

259. Hooft L, Hoekstra OS, Deville W, Lips P, Teule GJ, Boers M, van Tulder MW 2001 Diagnostic accuracy of 18F-fluorodeoxyglucose positron emission tomography in the follow-up of papillary or follicular thyroid cancer. J Clin Endocrinol Metab 86:3779-3786.

260. Sarlis NJ 2001 Metastatic thyroid cancer unresponsive to conventional therapies: Novel management approaches through translational clinical research. Curr Drug Targets Immune Endocr Metabol Disord 1:103-115.

261. Luster M, Lippi F, Jarzab B, Perros P, Lassmann M, Reiners C, Pacini F 2005 rhTSH-aided radioiodine ablation and treatment of differentiated thyroid carcinoma: A comprehensive review. Endocr Relat Cancer 12:49-64.

262. Van Tol KM, Hew JM, Jager PL, Vermey A, Dullaart RP, Links TP 2000 Embolization in combination with radioiodine therapy for bone metastases from differentiated thyroid carcinoma. Clin Endocrinol (Oxf) 52:653-659.

263. Posteraro AF, Dupuy DE, Mayo-Smith WW 2004 Related radiofrequency ablation of bony metastatic disease. Clin Radiol 59:803-811.

264. Hellman RS, Krasnow AZ 1998 Radionuclide therapy for palliation of pain due to osteoblastic metastases. J Palliative Med 1:277-283.

265. McWilliams RR, Giannini C, Hay ID, Atkinson JL, Stafford SL, Buckner JC 2003 Management of brain metastases from thyroid carcinoma: A study of 16 pathologically confirmed cases over 25 years. Cancer 98:356-362.

266. Kloos RT, Duvuuri V, Jhiang SM, Cahill KV, Foster JA, Burns JA 2002 Nasolacrimal drainage system obstruction from radioactive iodine therapy for thyroid carcinoma. J Clin Endocrinol Metab 87:5817-5820.
267. Rubino C, de Vathaire F, Dottorini ME, Hall P, Schvartz C, Couette JE, Dondon MG, Abbas MT, Langlois C, Schlumberger M 2003 Second primary malignancies in thyroid cancer patients. Br J Cancer 89:1638-1644.

268. Mandel SJ, Mandel L 2003 Radioactive iodine and the salivary glands. Thyroid 13:265-271.

269. Nakada K, Ishibashi T, Takei T, Hirata K, Shinohara K, Katoh S, Zhao S, Tamaki N, Noguchi Y, Noguchi S 2005 Does lemon candy decrease salivary gland damage after radioiodine therapy for thyroid cancer? J Nucl Med 46:261-266.

270. Chen AY, Levy L, Goepfert H, Brown BW, Spitz MR, Vassilopoulou-Sellin R 2001 The development of breast carcinoma in women with thyroid carcinoma. Cancer 92:225-231.

271. Vini, L, Hyer S, Al-Saadi A, Pratt B, Harmer C 2002 Prognosis for fertility and ovarian function after treatment with radioiodine for thyroid cancer. Postgrad Med J 78: 92-93.

272. Dottorini ME, Lomuscio G, Mazzucchelli L, Vignati A, Colombo L 1995 Assessment of female fertility and carcinogenesis after iodine-131 therapy for differentiated thyroid carcinoma. J Nucl Med 36:21-27.

273. Schlumberger M, De Vathaire F, Ceccarelli C, Delisle MJ, Francese C, Couette JE, Pinchera A, Parmentier C 1996 Exposure to radioactive iodine-131 for scintigraphy or therapy does not preclude pregnancy in thyroid cancer patients. J Nucl Med 37:606-612.

274. Ceccarelli C, Benicivelli W, Morciano D, Pinchera A, Pacini F 2001 I-131 therapy for differentiated thyroid cancer leads to an earlier onset of menopause: Results of a retrospective study. J Clin Endocrinol Metab 86:3512.

275. Wichers M, Benz E, Palmedo H, Biersack HJ, Grunwald F, Klingmuller D 2000 Testicular function after radioiodine therapy for thyroid carcinoma. Eur J Nucl Med 503-507.

276. Hyer S, Vini L, O'Connell M, Pratt B, Harmer C 2002 Testicular dose and fertility in men following I(131) therapy for thyroid cancer. Clin Endocrinol (Oxf) 56:755-758.

277. Lushbaugh CC, Casarett GW 1976 The effects of gonadal irradiation in clinical radiation therapy: A review. Cancer 37:1111-1125.

278. Sakar SD, Beierwaltes WH, Gill SP, Cowley BJ 1976 Subsequent fertility and birth histories of children and adolescents treated with I-131 for thyroid cancer. J Nucl Med 17:460.

279. Mazzaferri E 2002 Gonadal damage from 131I therapy for thyroid cancer. Clin Endocrinol 57:313-314.

280. van Tol KM, Jager PL, de Vries EG, Piers DA, Boezen HM, Sluiter WJ, Dullaart RP, Links TP 2003 Outcome in patients with differentiated thyroid cancer with negative diagnostic whole-body scanning and detectable stimulated thyroglobulin. Eur J Endocrinol 148:589-596.

281. Pineda JD, Lee T, Ain K, Reynolds JC, Robbins J 1995 Iodine-131 therapy for thyroid cancer patients with elevated thyroglobulin and negative diagnostic scan. J Clin Endocrinol Metab 80:1488-1492.

282. Pacini F, Agate L, Elisei R, Capezzone M, Ceccarelli C, Lippi F, Molinaro E, Pinchera A 2001 Outcome of differentiated thyroid cancer with detectable serum thyroglobulin and negative diagnostic (131)I whole body scan: Comparison of patients treated with high (131)I activities versus untreated patients. J Clin Endocrinol Metab 86:4092-4097. 
283. Kabasakal L, Selcuk NA, Shafipour H, Ozmen O, Onsel C, Uslu I 2004 Treatment of iodine-negative thyroglobulinpositive thyroid cancer: Differences in outcome in patients with macrometastases and patients with micrometastases. Eur J Nucl Med Mol Imaging 31:1500-1504.

284. Wang W, Macapinlac H, Larson SM, Yeh SD, Akhurst T, Finn RD, Rosai J, Robbins RJ 1999 [18F]-2-fluoro-2-deoxyD-glucose positron emission tomography localizes residual thyroid cancer in patients with negative diagnostic (131)I whole body scans and elevated serum thyroglobulin levels. J Clin Endocrinol Metab 84:2291-2302.

285. Helal BO, Merlet P, Toubert ME, Franc B, Schvartz C, Gauthier-Koelesnikov H, Prigent A, Syrota A 2001 Clinical impact of (18)F-FDG PET in thyroid carcinoma patients with elevated thyroglobulin levels and negative (131)I scanning results after therapy. J Nucl Med 42:1464-1469.

286. Chin BB, Patel P, Cohade C, Ewertz M, Wahl R, Ladenson P. 2004 Recombinant human thyrotropin stimulation of fluoro-D-glucose positron emission tomography uptake in well-differentiated thyroid carcinoma. J Clin Endocrinol Metab 89:91-95.

287. Nahas Z, Goldenberg D, Fakhry C, Ewertz M, Zeiger M, Ladenson PW, Wahl R, Tufano RP. 2005 The role of positron emission tomography/computed tomography in the management of recurrent papillary thyroid carcinoma. Laryngoscope 115:237-243.

288. Gottlieb JA, Hill CS Jr, Ibanez ML, Clark RL 1992 Chemotherapy of thyroid cancer. An evaluation of experience with 37 patients. Cancer 30:848-853.

289. Gottlieb JA, Hill CS Jr 1974 Chemotherapy of thyroid cancer with adriamycin. Experience with 30 patients. N Engl J Med 290:93-197.

290. O’Bryan RM, Baker LH, Gottlieb JE, Rivkin SE, Balcerzak SP, Grumet GN, Salmon SE, Moon TE, Hoogstraten B 1977 Dose response evaluation of adriamycin in human neoplasia. Cancer 39:1940-1948.

291. Pacini F, Vitti P, Martino E, Giani C, Bambini G, Pinchera A, Bascheri L 1984 Treatment of refractory thyroid cancer with adriamycin. Drugs Experimental Clinical Research 10:911-916.

292. Haugen BR 1999 Management of the patient with progressive radioiodine non-responsive disease. Semin Surg Oncol 16:34-41.

293. Ain KB, Egorin MJ, DeSimone PA 2000 Treatment of anaplastic thyroid carcinoma with paclitaxel: Phase 2 trial using ninety-six-hour infusion. Collaborative Anaplastic Thyroid Cancer Health Intervention Trials (CATCHIT) Group. Thyroid 10:587-594.

294. Santini F, Bottici V, Elisei R, Montanelli L, Mazzeo S, Basolo F, Pinchera A, Pacini F 2002 Cytotoxic effects of carboplatinum and epirubicin in the setting of an elevated serum thyrotropin for advanced poorly differentiated thyroid cancer. J Clin Endocrinol Metab 87:4160-4165.

295. Rosario PW, Maia FF, Fagundes TA, Vasconcelos FP, Cardoso LD, Purisch S 2004 Antithyroglobulin antibodies in patients with differentiated thyroid carcinoma: Methods of detection, interference with serum thyroglobulin measurement and clinical significance. Arq Bras Endocrinol Metabol 48:487-492.

296. Chung JK, Park YJ, Kim TY, So Y, Kim SK, Park DJ, Lee DS, Lee MC, Cho BY 2002 Clinical significance of elevated level of serum antithyroglobulin antibody in patients with differentiated thyroid cancer after thyroid ablation. Clin Endocrinol 57:215-221.

297. Chinnappa P, Taguba L, Arciaga R, Faiman C, Siperstein A, Mehta AE, Reddy SK, Nasr C, Gupta MK 2004 Detection of thyrotropin-receptor messenger ribonucleic acid (mRNA) and thyroglobulin mRNA transcripts in peripheral blood of patients with thyroid disease: Sensitive and specific markers for thyroid cancer. J Clin Endocrinol Metab 89:3705-3709.

298. Li D, Butt A, Clarke S, Swaminathana R 2004 Real-time quantitative PCR measurement of thyroglobulin mRNA in peripheral blood of thyroid cancer patients and healthy subjects. Ann NY Acad Sci 1022:147-151.

299. Grammatopoulos D, Elliott Y, Smith SC, Brown I, Grieve RJ, Hillhouse EW, Levine MA, Ringel MD 2003 Measurement of thyroglobulin mRNA in peripheral blood as an adjunctive test for monitoring thyroid cancer. Mol Pathol 56:162-166.

300. Elisei R, Vivaldi A, Agate L, Molinaro E, Nencetti C, Grasso L, Pinchera A, Pacini F 2004 Low specificity of blood thyroglobulin messenger ribonucleic acid assay prevents its use in the follow-up of differentiated thyroid cancer patients. J Clin Endocrinol Metab 89:33-39.

301. Bellantone R, Lombardi CP, Bossola M, Ferrante A, Princi $\mathrm{P}$, Boscherini M, Maussier L, Salvatori M, Rufini V, Reale F, Romano L, Tallini G, Zelano G, Pontecorvi A 2001 Validity of thyroglobulin mRNA assay in peripheral blood of postoperative thyroid carcinoma patients in predicting tumor recurrences varies according to the histologic type: Results of a prospective study. Cancer 92:2273-2279.

Address reprint requests to: Barbara Rath Smith, CAE Executive Director

American Thyroid Association 6066 Leesburg Pike

Suite 550

Falls Church, VA 22041-2222

E-mail: bsmith@thyroid.org 
November 16, 2005

AMERICAN

THYROID

ASSOCIATION

FOUNDED 1923

2005-2006

President

Enest L. Mazzaferri, M.D.

Gainesville, Florida

Secretary

Gregory A. Brent, M.D.

Los Angeles, California

Treasurer

Chatles H. Emetson, M.D.

Worcester, Massachusetts

President-Elect

David S. Cooper, M.D.

Baltimore, Maryland

Directors

Paul W. Ladenson, M.D. (2006)

Baltimore, Maryland

Rebecca S. Bahn, M.D. (2006)

Rochester, Minnesota

Donald L. St. Germain, M.D. (2006)

Lebanon, New Hampshite

Bryan R. Haugen, M.D. (2007)

Denver, Colorado

Sandra M. McLachlan, Ph.D. (2007)

Los Angeles, California

Gilbert H. Daniels, M.D. (2008)

Boston, Massachusetts

Steven I. Sherman, M.D. (2008)

Houston, Texas

Matthew D. Ringel, M.D. (2009)

Columbus, Ohio

Mary H. Samuels, M.D. (2009)

Portland, Oregon

Executive Director

Barbara R. Smith, CAE

Headquarters Office

American Thyroid Association

6066 Leesburg Pike, Suite 550

Falls Church, Virginia 22041

Phone: 703 998-8890

Fax: $\quad 703$ 998-8893

E-mail: bsmith@thyroid.org

Web: www.thyroid.org
Terry Davies, MD

Editor-in-Chief

THYROID

Dear Dr. Davies:

I am writing this letter to accompany the submission of the manuscript "MANAGEMENT GUIDELINES FOR PATIENTS WITH THYROID NODULES AND DIFFERENTIATED THYROID CANCER" under evaluation for publication in THYROID. Dr. David Cooper, the corresponding author, is acting on behalf of the officers and council of the American Thyroid Association who have reviewed and approved of these guidelines as an official position of our organization. Dr. Cooper will coordinate any necessary clarifications or revisions of these guidelines on behalf of the ATA.

Thank you for considering these guidelines for publication.

Regards,
Suneot f. Magafen
Ernest L. Mazzaferri, MD

President

American Thyroid Association

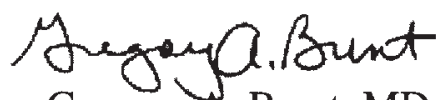

Gregory A. Brent, MD

Secretary

American Thyroid Association
Cc: Barbara Smith, Executive Director, American Thyroid Association 